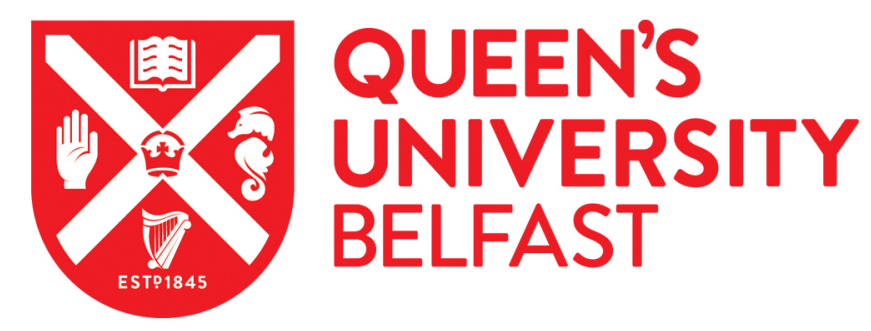

\title{
Improved model for interfacial stresses accounting for the effect of shear deformation in plated beams
}

Narayanamurthy, V., Chen, J. F., \& Cairns, J. (2016). Improved model for interfacial stresses accounting for the effect of shear deformation in plated beams. International Journal of Adhesion and Adhesives, 64, 33-47. https://doi.org/10.1016/j.ijadhadh.2015.10.001

Published in:

International Journal of Adhesion and Adhesives

Document Version:

Peer reviewed version

Queen's University Belfast - Research Portal:

Link to publication record in Queen's University Belfast Research Portal

Publisher rights

(C) 2015 Elsevier.

This manuscript version is made available under the CC-BY-NC-ND 4.0 licensehttp://creativecommons.org/licenses/by-nc-nd/4.0/,which permits distribution and reproduction for non-commercial purposes, provided the author and source are cited.

\section{General rights}

Copyright for the publications made accessible via the Queen's University Belfast Research Portal is retained by the author(s) and / or other copyright owners and it is a condition of accessing these publications that users recognise and abide by the legal requirements associated with these rights.

Take down policy

The Research Portal is Queen's institutional repository that provides access to Queen's research output. Every effort has been made to ensure that content in the Research Portal does not infringe any person's rights, or applicable UK laws. If you discover content in the Research Portal that you believe breaches copyright or violates any law, please contact openaccess@qub.ac.uk. 


\title{
IMPROVED MODEL FOR INTERFACIAL STRESSES ACCOUNTING FOR THE EFFECT OF SHEAR DEFORMATION IN PLATED BEAMS
}

\author{
V. Narayanamurthy ${ }^{l}$, J.F. Chen ${ }^{2,}{ }^{*}$ and J. Cairns ${ }^{3}$ \\ 1 Directorate of Systems Integration (Mechanical), Research Centre Imarat, Hyderabad- 500 \\ 069, India \\ 2 School of Planning, Architecture and Civil Engineering, Queen's University Belfast, Belfast \\ BT9 5AG, UK \\ School of the Built Environment, Heriot-Watt University, Edinburgh, UK \\ * Corresponding author \\ School of Planning, Architecture and Civil Engineering \\ David Keir Building \\ Queen's University Belfast \\ Belfast BT9 5AG, UK \\ Tel.: +44 (0)28 9097 4184, Fax: +44 (0)289097 4278, Email: j.chen@qub.ac.uk
}

\begin{abstract}
A significant increase in strength and performance of reinforced concrete, timber and metal beams may be achieved by adhesively bonding a fibre reinforced polymer composite, or metallic such as steel plate to the tension face of a beam. One of the major failure modes in these plated beams is the debonding of the plate from the original beam in a brittle manner. This is commonly attributed to the interfacial stresses between the adherends whose quantification has led to the development of many analytical solutions over the last two decades. The adherends are subjected to axial, bending and shear deformations. However, most analytical solutions have neglected the effect of shear deformation in adherends. Few solutions consider this effect approximately but are limited to one or two specific loading conditions. This paper presents a more rigorous solution for interfacial stresses in plated beams under an arbitrary loading with the shear deformation of the adherends duly considered in closed form using Timoshenko's beam theory. The solution is general to linear elastic analysis of prismatic beams of arbitrary cross section under arbitrary loading with a plate of any thickness bonded either symmetrically or asymmetrically with respect to the span of the beam.
\end{abstract}

Keywords: Beam; FRP composite; Strengthening; Interfacial stresses; Beam theory; Closedform solution 


\section{INTRODUCTION}

Reinforced concrete (RC), metal or timber beams may be strengthened by adhesively bonding a fibre reinforced polymer (FRP) composite, steel or other metal plate to the soffit of the beam (Fig. 1). Such a strengthened beam is commonly termed a plated beam. This strengthening technique has become widely accepted in structural engineering for retrofitting and strengthening of existing structures, with FRP plating in particular being extensively employed. Under external loading, forces are transferred between beam and plate, generating interfacial shear and normal stresses in the adhesive layer between the adherends. Their concentration is highest at the plate ends due to the presence of a geometric discontinuity and their combination is believed to be responsible for the brittle debonding mode of failure commonly observed in tests which occurs well before the full flexural strength of the plated beam is reached.

Consequently, the interfacial stresses between the plate and the original beam have attracted a great interest in the last two decades and many analytical solutions [1-21] have been developed to quantify them. Among them, Smith and Teng [8] is simple, accurate and the most popular. All except Narayanamurthy et al. [20] and Zhang and Teng [21] are applicable only to one or a few specific loading conditions. Both are applicable to any loading arrangement and are simpler than and retain the accuracy of Smith and Teng [8]. All these but $[7,9,13,14]$ are considered to be 'classical' solutions as they assume invariant stresses through the thickness of the adhesive layer and hence violate the free surface condition at the ends of the adhesive layer. However, as this affects the solution only within a few millimetres from the plate ends [2], classical solutions still offer useful insights of the behaviour of plated beams.

Higher order solutions $[7,9,13,14]$ consider varying stresses through the thickness of the adhesive layer and satisfy the stress-free condition at the plate ends. However, they are complex to develop and difficult to adopt in practice because of stress singularity at the bimaterial (adhesive and substrate) interface at the plate ends. This paper derives a closed-form solution similar to the classical solutions but which includes shear deformations in the adherends. A higher order solution is beyond the scope of this paper.

The adherends in a plated beam are generally subjected to axial, bending and shear deformations under external loading. However, most theoretical solutions neglect the effect of shear deformation of the adherends. Liu and Zhu [4] considered the effect of shear deformation of the beam only in their general solution of interfacial shear stress but provided an incomplete solution, omitting expressions for the constants of integration. Smith and Teng [8] considered the shear deformation of the adherends within the governing differential equations but neglected it when deriving the general solutions to avoid complexities in obtaining general solutions from the two strongly coupled governing equations. Abdelouahed [17,22] (applicable to UDL and single point loads) and Yang and Wu [18] (applicable to UDL only) adopted the solution of Smith and Teng [8] and included the shear deformation effect only approximately in the solution of interfacial shear stress. Their solutions suggest that the effect of shear deformation predominates on interfacial shear stress but is negligible for interfacial normal stress, although the present solution and finite element (FE) predictions will demonstrate that this is not necessarily correct. Narayanamurthy et al. [23] (applicable to all loading arrangements) includes an approximation to the effect of shear deformation on the interfacial shear stress and used Timoshenko's beam theory to derive interfacial normal stress. This is the first closed-form solution that included the effects of adherend's shear deformation on both interfacial shear and normal stresses in plated beams. Although the formulation for interfacial normal stress is accurate, its accuracy is compromised by the approximation 
involved in interfacial shear stress. These four solutions have adopted different approximations to overcome mathematical difficulties in arriving at their general solutions. Recently Edalati and Irani [24] provided a solution applicable only to a UDL by considering all three deformations in adherends in closed-form but it predicted a reduction in interfacial normal stress when compared with that of Smith and Teng [8], the opposite trend to that predicted by FE analyses as well as by the solution presented here. The actual effect of adherends' shear deformation is not yet clearly understood.

The effect of shear deformations has been investigated in adhesively bonded single and double lap joints subjected to axial loading. Delale et al. [25] modelled the stresses in single lap joints made of orthotropic adherends which were assumed to be very thin compared to the lateral dimensions and used Reissner's plate theory in a plane strain state. Tsai et al. [26] considered the shear deformation in double lap joints under tension by assuming a linear shear stress variation through the thickness of the adherends and treated the adherends as two thin beams, instead of thin plates as in Delale et al. [25]. Many other important interfacial stress solutions for double lap joints under axial loading are reviewed in detail by Chalkley and Rose [27]. These solutions highlight that the accuracy of the predicted interfacial stresses can be improved by considering the shear deformations of the adherends, but they clearly cannot be directly applied to the present problem because of the differences in both structural form and loading conditions.

Further, the shear deformation effect in multilayered composites and sandwich plates loaded by transverse pressure with various in-plane distributions has been studied by Carerra and Ciuffreda [28] using a unified formulation. They compared about forty theories based on equivalent single layer models and layer-wise models within the framework of principle of virtual displacement and Reissner's mixed variational theorem and presented a closed form solution for orthotropic plates by expanding the applied pressure loading in Fourier series. These models for orthotropic plates with transverse pressure loading are clearly not adaptable to predict the interfacial stresses in plated beams with geometrical discontinuities. Recently, Cui et al. [29] developed an analytical solution for the 'short beam shear' test configuration to measure the shear properties of adhesive bonding in terms of deflection and stress distributions. They used it to predict the adhesive layer's shear modulus with better accuracy than existing solutions for both thin and thick adhesive layers. This solution is also not directly related and cannot be applied to the type of problems discussed in the present paper.

The solution presented in this paper is based on the principle of superposition and includes the simultaneous effects of axial, bending and shear deformation of the adherends of a plated beam on both interfacial shear and normal stresses in closed-form using Timoshenko's beam theory. The coupled governing differential equations of interfacial shear and normal stresses are solved and the general solutions are obtained by employing appropriate conditions for plated beams. The solution is general in nature, applicable to any linear elastic plated beams, with any prismatic beam cross sections, plate bonded symmetrically or asymmetrically over the span of the beam, and under any loading arrangements. The solution is compared with previous analytical solutions as well as FE predictions for a sample plated beam.

\section{ASSUMPTIONS}

The following assumptions are employed in deriving the rigorous solution in this paper:

a) the beam, adhesive and plate are linear elastic; 
b) the shear and normal stresses in the adhesive layer are constant through its thickness although the shear stress variation is partially captured within the capability of the composite beam theory;

c) the curvature of the beam and the plate are the same when deriving the interfacial shear stress. This assumption is not used when deriving the interfacial normal stress;

d) there is no slip or separation between the beam and the adhesive and between the adhesive and the plate; and

e) the original beam and the plate are treated as two Timoshenko beams.

\section{METHODOLOGY}

Consider a simply supported beam symmetrically or asymmetrically strengthened with a soffit plate as in Fig. 1. The plated beam under an arbitrary loading as shown in Case-1 (Fig. 2) is decomposed into Case-2 and Case-3. Case-2 includes all the external loading in addition to an axial force, a shear force and a bending moment at each end of the plate. The magnitude of these axial forces, shear forces and moments are determined from the deformation of the un-plated beam so that both ends of the plate deform compatibly with the un-plated beam under the external loading and the case can be analysed using the classical composite beam theory. Case- 3 is the plated beam under the same but opposite plate end loading as in Case-2. The combined solution from Cases 2 and 3 gives the solution for the original problem in Case-1.

Let the axial and bending stiffness ratios of the plate to the beam be $R_{a}$ and $R_{b}$ respectively and the ratio between the axial stiffness of the plate and the bending stiffness of the beam be $R_{a b}$

$$
R_{a}=\frac{E_{2} A_{2}}{E_{1} A_{1}} ; \quad R_{b}=\frac{E_{2} I_{2}}{E_{1} I_{1}} ; \quad R_{a b}=\frac{E_{2} A_{2}}{E_{1} I_{1}}
$$

The axial force $N$, shear force $V$ and bending moment $M$ at the plate ends for the composite beam in Case-2 (Fig. 2) are given as:

$$
\begin{aligned}
& N_{p l}=M(0)\left(y_{1}+t_{a}+y_{2}\right) R_{a b}+N R_{a} \\
& N_{p r}=M\left(L_{p}\right)\left(y_{1}+t_{a}+y_{2}\right) R_{a b}+N R_{a} \\
& V_{p l}=\frac{E_{2} b_{2} t_{2}^{2}\left[2 t_{2}+3\left(t_{1}+t_{a}-y_{c}\right)\right]}{6 E_{1} I_{e}} V(0) \\
& V_{p r}=\frac{E_{2} b_{2} t_{2}^{2}\left[2 t_{2}+3\left(t_{1}+t_{a}-y_{c}\right)\right]}{6 E_{1} I_{e}} V\left(L_{p}\right) \\
& M_{p l}=M(0) R_{b} \\
& M_{p r}=M\left(L_{p}\right) R_{b}
\end{aligned}
$$

where subscripts $p l$ and $p r$ refer respectively to the left and right plate ends; subscripts $1, a$ and 2 respectively denote the original beam (adherend-1), adhesive and plate (adherend-2); $M(0), M\left(L_{p}\right), V(0)$ and $V\left(L_{p}\right)$ denote the bending moments and shear forces at $x=0$ and $x=L_{p}$ respectively on the beam under only the original loading; $E, A, I, I_{\mathrm{e}}, b$ and $t$ denote the elastic modulus, cross sectional area, second moment of area about the centroid of the concerned adherend, equivalent second moment of area of the composite beam section, breadth and thickness respectively; and $y_{1}$ and $y_{2}$ are the distances from the bottom of the adherend- 1 (the original beam) and the top of the adherend-2 (the plate) to their respective centroids and $y_{c}$ is the distance of the centroid of the composite beam section from the top surface. 


\section{SOLUTION FOR THE COMPOSITE BEAM (CASE-2)}

As noted earlier the interfacial stresses in Case- 2 can be obtained using the classical composite beam analysis. The equivalent second moment of area of the composite beam section is given by

$$
I_{e}=I_{1 c}+I_{a c}+I_{2 c}
$$

where $I_{1 c}, I_{a c}$ and $I_{2 c}$ are the equivalent second moment of area of the original beam, adhesive and plate sections respectively about the centroid of the composite beam section:

$$
\begin{aligned}
& I_{1 c}=I_{1}+A_{1}\left[y_{c}-\left(t_{1}-y_{1}\right)\right]^{2} \\
& I_{a c}=\left[\frac{b_{a} t_{a}^{3}}{12}+b_{a} t_{a}\left(t_{1}+0.5 t_{a}-y_{c}\right)^{2}\right] R_{m a} \\
& I_{2 c}=\left[\frac{b_{2} t_{2}^{3}}{12}+b_{2} t_{2}\left(t_{1}+t_{a}+y_{2}-y_{c}\right)^{2}\right] R_{m 2}
\end{aligned}
$$

in which $y_{c}$ and the modular ratios $R_{m a}$ and $R_{m 2}$ are given by

$$
\begin{aligned}
& y_{c}=\frac{A_{1}\left(t_{1}-y_{1}\right)+R_{m a} b_{a} t_{a}\left(t_{1}+0.5 t_{a}\right)+R_{m 2} b_{2} t_{2}\left(t_{1}+t_{a}+y_{2}\right)}{A_{1}+R_{m a} b_{a} t_{a}+R_{m 2} b_{2} t_{2}} \\
& R_{m a}=\frac{E_{a}}{E_{1}} ; \quad R_{m 2}=\frac{E_{2}}{E_{1}}
\end{aligned}
$$

Considering a point in the adhesive layer with distance $y$ from the beam to adhesive interface (so $y$ ranges from 0 to $t_{a}$ within the adhesive), the first moment of area of the equivalent plate and adhesive section below the considered position about the centroid of the composite beam section is given by

$$
Q_{e}(y)=R_{m 2} b_{2} t_{2}\left[t_{1}+t_{a}+y_{2}-y_{c}\right]+R_{m a} b_{2}\left(t_{a}-y\right)\left[t_{1}+0.5\left(t_{a}+y\right)-y_{c}\right]
$$

The shear stress at the considered position within the adhesive layer is thus

$$
\tau(x, y)=m_{c}(y) V_{T c}(x)
$$

where $V_{T c}(x)$ is the total shear force on the composite beam section at a distance $x$ from the left plate end due to all the loading in Case-2 and

$$
m_{c}(y)=\frac{Q_{e}(y)}{I_{e} b_{2}}
$$

The interfacial normal stress from this theory is zero: $\sigma(x) \approx 0$.

\section{GOVERNING DIFFERENTIAL EQUATIONS FOR CASE-3}

The governing differential equations for the interfacial shear and normal stresses between the adherends for the plated beam shown in Case-3 (Fig. 2) are derived in this section.

\section{Interfacial shear stress}

The moment in the beam and the plate can be related assuming compatibility of curvatures:

$$
R_{b} M_{1}(x)=M_{2}(x)
$$

Longitudinal equilibrium of a differential segment of the plated beam as shown in Fig. 3 gives

$$
-\frac{d N_{1}(x)}{d x}=b_{2} \tau(x)=\frac{d N_{2}(x)}{d x}
$$


where $\tau(x)$ is the interfacial shear stress between the adherends.

Eq. 18 and axial equilibrium of the left part of the structure gives

$$
N_{p l}-N_{p r}-N_{1}(x)=b_{2} \int_{0}^{x} \tau(x) d x=N_{2}(x)+N_{p l}
$$

The total shear force $V_{T}(x)$ and total applied moment $M_{T}(x)$ at any section of the plated beam as obtained from plate end loadings in Fig. 2 are

$$
\begin{array}{ll}
V_{T}(x)=\frac{1}{L}\left[M_{p l}-M_{p r}-\left(V_{p l} a_{l}+V_{p r} a_{r}\right)+\left(N_{p l}-N_{p r}\right)\left(t_{a}+y_{2}\right)\right]=V_{T} & \\
M_{T}(x)=V_{p l} a_{l}+V_{T}\left(a_{l}+x\right)-M_{p l}-N_{p l}\left(t_{a}+y_{2}\right)-N_{p r}\left(t_{1}-y_{c}\right) ; \quad 0 \leq x \leq L_{p}
\end{array}
$$

where $a_{l}$ and $a_{r}$ are respectively the distances from the left and right plate ends to the left and right supports as shown in Fig. 1.

$M_{T}(x)$ can also be expressed as a function of the adherend moments, interfacial shear stress and plate end axial forces and using Eq. 19 as

$$
M_{T}(x)=M_{1}(x)+M_{2}(x)+\left(b_{2} \int_{0}^{x} \tau(x) d x-N_{p l}\right)\left(y_{1}+t_{a}+y_{2}\right)+N_{p r}\left(y_{c}-t_{1}+y_{1}\right)
$$

From Eqs 17 and 22 the bending moment in each adherend can be found as

$$
M_{i}(x)=\frac{E_{i} I_{i}}{E_{1} I_{1}+E_{2} I_{2}}\left[M_{T}(x)-\left(b_{2} \int_{0}^{x} \tau(x) d x-N_{p l}\right)\left(y_{1}+t_{a}+y_{2}\right)-N_{p r}\left(y_{c}-t_{1}+y_{1}\right)\right]
$$

where subscript $i=1,2$.

The first derivative of Eq. 23 relates the bending moment in each adherend to the total shear force:

$$
\frac{d M_{i}(x)}{d x}=\frac{E_{i} I_{i}}{E_{1} I_{1}+E_{2} I_{2}}\left[V_{T}(x)-b_{2}\left(y_{1}+t_{a}+y_{2}\right) \tau(x)\right] ; i=1,2
$$

The longitudinal strain at the bottom of adherend-1 $\varepsilon_{l}(x)$ and at the top of adherend-2 $\varepsilon_{2}(x)$ are

$$
\varepsilon_{i}(x)=\frac{d u_{i}(x)}{d x}=(-1)^{i+1} \frac{y_{i}}{E_{i} I_{i}} M_{i}(x)+\frac{1}{E_{i} A_{i}} N_{i}(x)+\frac{y_{i}}{G_{i} A_{i} \kappa_{i}} b_{2} \sigma(x) ; i=1,2
$$

where $\kappa$ is the Timoshenko's shear coefficient ( $\kappa=5 / 6$ for rectangular sections; $5 / 12$ for hollow thin walled square sections, etc,), $G$ is the transverse shear modulus of the adherends and $\sigma(x)$ is the interfacial normal stress.

Based on the theory of elasticity, the shear stress in the adhesive layer can be found from

$$
\tau(x)=G_{a}\left[\frac{d u(x, y)}{d y}+\frac{d v(x, y)}{d x}\right]
$$

where $G_{a}$ is the shear modulus of adhesive and $u(x, y)$ and $v(x, y)$ are the horizontal and vertical displacement in the adhesive layer.

The first derivative of Eq. 26 with respect to $x$ (w.r.t. $x$ ) is

$$
\frac{d \tau(x)}{d x}=G_{a}\left[\frac{d^{2} u(x, y)}{d x d y}+\frac{d^{2} v(x, y)}{d x^{2}}\right]
$$

Applying the moment-curvature relation for a differential segment of the plated beam yields 


$$
\frac{d^{2} v(x, y)}{d x^{2}}=-\frac{1}{E_{1} I_{e}} M_{T}(x)
$$

The shear stress is assumed to be uniform through the thickness of the adhesive layer in Case-

3 . Hence, $u(x, y)$ varies linearly across $t_{a}$ giving

$$
\frac{d u(x, y)}{d y}=\frac{1}{t_{a}}\left[u_{2}(x)-u_{1}(x)\right]
$$

The first derivative of this equation w.r.t. $x$ is

$$
\frac{d^{2} u(x, y)}{d x d y}=\frac{1}{t_{a}}\left[\frac{d u_{2}(x)}{d x}-\frac{d u_{1}(x)}{d x}\right]
$$

Substituting Eqs 28 and 30 into Eq. 27 gives

$$
\frac{d \tau(x)}{d x}=\frac{G_{a}}{t_{a}}\left[\frac{d u_{2}(x)}{d x}-\frac{d u_{1}(x)}{d x}\right]-\frac{G_{a}}{E_{1} I_{e}} M_{T}(x)
$$

Substituting Eqs 22 and 25 into Eq. 31 yields

$$
\frac{d \tau(x)}{d x}=\frac{G_{a}}{E_{1}}\left[-r_{1} M_{1}(x)-r_{2} M_{2}(x)-r_{3} N_{1}(x)+r_{4} N_{2}(x)\right]-\alpha_{1} \sigma(x)
$$

where

$$
\begin{aligned}
& r_{1}=\frac{y_{1}}{t_{a} I_{1}}+\frac{1}{I_{e}} \\
& r_{2}=\frac{y_{2}}{t_{a} R_{m 2} I_{2}}+\frac{1}{I_{e}} \\
& r_{3}=\frac{1}{t_{a} A_{1}}-\frac{\left(y_{c}-t_{1}+y_{1}\right)}{I_{e}} \\
& r_{4}=\frac{1}{t_{a} R_{m 2} A_{2}}-\frac{\left(t_{1}+t_{a}+y_{2}-y_{c}\right)}{I_{e}} \\
& \alpha_{1}=\frac{G_{a} b_{2}}{t_{a}}\left[\frac{y_{1}}{G_{1} A_{1} \kappa_{1}}-\frac{y_{2}}{G_{2} A_{2} \kappa_{2}}\right]
\end{aligned}
$$

Differentiating Eq. 32 once w.r.t.x and substituting Eqs 18 and 24 into the resulting expression results in the governing differential equation for the interfacial shear stress:

$$
\frac{d^{2} \tau(x)}{d x^{2}}-\lambda^{2} \tau(x)+m_{1} \lambda^{2} V_{T}(x)+\alpha_{1} \frac{d \sigma(x)}{d x}=0
$$

where

$$
\begin{aligned}
& \lambda^{2}=\frac{G_{a} b_{2}}{t_{a}}\left[\frac{\left(y_{1}+y_{2}\right)\left(y_{1}+t_{a}+y_{2}\right)}{\left(E_{1} I_{1}+E_{2} I_{2}\right)}+\frac{1}{E_{1} A_{1}}+\frac{1}{E_{2} A_{2}}\right] \\
& m_{1}=\frac{G_{a}}{\lambda^{2}}\left[\frac{y_{1}+y_{2}}{t_{a}\left(E_{1} I_{1}+E_{2} I_{2}\right)}+\frac{1}{E_{1} I_{e}}\right]
\end{aligned}
$$

\section{Interfacial normal stress}

The interfacial normal stress exists between the adherends due to the existence of a differential vertical displacement when the beam is loaded. Let the vertical displacements of adherends 1 and 2 be respectively $v_{1}(x)$ and $v_{2}(x)$, the interfacial normal stress $\sigma(x)$ can be found from: 


$$
\sigma(x)=\frac{E_{a}}{t_{a}}\left[v_{2}(x)-v_{1}(x)\right]
$$

The moment-curvature relationship, moment and vertical equilibrium of the differential segment of adherends 1 and 2 (Fig. 3) give the following relationships:

$$
\begin{aligned}
& \frac{d^{2} v_{i}(x)}{d x^{2}}=-\frac{1}{E_{i} I_{i}} M_{i}(x)+(-1)^{i} \frac{b_{2}}{G_{i} A_{i} \kappa_{i}} \sigma(x) ; \quad i=1,2 \\
& \frac{d M_{i}(x)}{d x}=V_{i}(x)-b_{2} y_{i} \tau(x) ; \quad i=1,2 \\
& \frac{d V_{i}(x)}{d x}=(-1)^{i} b_{2} \sigma(x) ; \quad i=1,2
\end{aligned}
$$

Differentiating Eq. 35 once w.r.t. $x$ and substituting Eq. 36 into the resulting equation gives:

$$
\frac{d^{3} v_{i}(x)}{d x^{3}}=-\frac{1}{E_{i} I_{i}}\left(V_{i}(x)-b_{2} y_{i} \tau(x)\right)+(-1)^{i} \frac{b_{2}}{G_{i} A_{i} \kappa_{i}} \frac{d \sigma(x)}{d x} ; \quad i=1,2
$$

Differentiating Eq. 38 once w.r.t. $x$ and substituting Eq. 37 into the resulting equation gives:

$$
\frac{d^{4} v_{i}(x)}{d x^{4}}=(-1)^{i+1} \frac{b_{2}}{E_{i} I_{i}} \sigma(x)+(-1)^{i} \frac{b_{2}}{G_{i} A_{i} \kappa_{i}} \frac{d^{2} \sigma(x)}{d x^{2}}+\frac{b_{2} y_{i}}{E_{i} I_{i}} \frac{d \tau(x)}{d x} ; \quad i=1,2
$$

Differentiating Eq. 34 four times w.r.t. $x$ and substituting Eq. 39 into the resulting equation yields the following governing differential equation for the interfacial normal stress:

$$
\frac{d^{4} \sigma(x)}{d x^{4}}-\beta_{1} \frac{d^{2} \sigma(x)}{d x^{2}}+\beta_{2} \sigma(x)+n_{2} \frac{d \tau(x)}{d x}=0
$$

where

$$
\begin{aligned}
& \beta_{1}=\frac{E_{a} b_{2}}{t_{a}}\left[\frac{1}{G_{1} A_{1} \kappa_{1}}+\frac{1}{G_{2} A_{2} \kappa_{2}}\right] \\
& \beta_{2}=\frac{E_{a} b_{2}}{t_{a}}\left[\frac{1}{E_{1} I_{1}}+\frac{1}{E_{2} I_{2}}\right] \\
& n_{2}=\frac{E_{a} b_{2}}{t_{a}}\left[\frac{y_{1}}{E_{1} I_{1}}-\frac{y_{2}}{E_{2} I_{2}}\right]
\end{aligned}
$$

In Eq. 40, $\beta_{1}$ arose from Timoshenko's beam theory and reflects the effect of shear deformation. If $\beta_{1}=0$ it reduces to the governing equation for interfacial normal stress without considering shear deformation as in Narayanamurthy et al. [20].

\section{Uncoupling of governing differential equations}

The governing differential equations for the interfacial shear and normal stresses [Eqs 33 and 40] are coupled and hence a general solution is not easily found. This coupling arises due to the introduction of the shear deformation effect in the adherends. To circumvent this difficulty, most previous researchers have neglected the shear deformation either from the beginning or at a late stage from the governing differential equations. A few others resorted to approximate methods or numerical techniques. A simple procedure is adopted here in uncoupling the governing equations which makes it possible to obtain a closed-form solution for the interfacial stresses.

Integrating Eq. 33 w.r.t.x gives,

$$
\sigma(x)=\frac{1}{\alpha_{1}}\left(C-\frac{d \tau(x)}{d x}+\lambda^{2} \int \tau(x) d x-m_{1} \lambda^{2} \int V_{T}(x) d x\right)
$$


where $C$ is the constant of integration and vanishes in the subsequent operations.

Substituting the second and forth derivative of $\sigma(x)$ from Eq. 41 into Eq. 40 and differentiating the resulting expression once w.r.t. $x$ yields an uncoupled GDE for the interfacial shear stress as

$$
\frac{d^{6} \tau(x)}{d x^{6}}-\alpha_{2} \frac{d^{4} \tau(x)}{d x^{4}}+\alpha_{3} \frac{d^{2} \tau(x)}{d x^{2}}-\alpha_{4} \tau(x)+\alpha_{5} V_{T}(x)=0
$$

where

$$
\begin{aligned}
& \alpha_{2}=\beta_{1}+\lambda^{2} \\
& \alpha_{3}=\beta_{1} \lambda^{2}+\beta_{2}-n_{2} \alpha_{1} \\
& \alpha_{4}=\beta_{2} \lambda^{2} \\
& \alpha_{5}=\beta_{2} m_{1} \lambda^{2}
\end{aligned}
$$

\section{BOUNDARY CONDITIONS IN CASE-3}

The boundary conditions available in Case-3 are:

$$
\begin{aligned}
\left.M_{1}(x)\right|_{x=0}=\frac{a_{l}}{L}\left[\left(L-a_{l}\right) V_{p l}-a_{r} V_{p r}+M_{p l}-M_{p r}+\left(N_{p l}-N_{p r}\right)\left(\frac{L}{a_{l}} y_{1}+y_{2}+t_{a}\right)\right]=M_{1}(0) \\
\left.M_{2}(x)\right|_{x=0}=-M_{p l} \\
\left.N_{1}(x)\right|_{x=0}=N_{p l}-N_{p r} \\
\left.N_{2}(x)\right|_{x=0}=-N_{p l} \\
\left.V_{1}(x)\right|_{x=0}=V_{T}+V_{p l}-\left.b_{2} t_{a} \tau(x)\right|_{x=0} \\
\left.V_{2}(x)\right|_{x=0}=-V_{p l} \\
\left.M_{1}(x)\right|_{x=L_{p}}=\frac{a_{r}}{L}\left[a_{l} V_{p l}-\left(L-a_{r}\right) V_{p r}-M_{p l}+M_{p r}-\left(N_{p l}-N_{p r}\right)\left(y_{2}+t_{a}\right)\right]=M_{1}\left(L_{p}\right) \\
\left.M_{2}(x)\right|_{x=L_{p}}=-M_{p r} \\
\left.N_{1}(x)\right|_{x=L_{p}}=0 \\
\left.N_{2}(x)\right|_{x=L_{p}}=-N_{p r} \\
\left.V_{1}(x)\right|_{x=L_{p}}=V_{T}+V_{p r}-\left.b_{2} t_{a} \tau(x)\right|_{x=L_{p}} \\
\left.V_{2}(x)\right|_{x=L_{p}}=-V_{p r}
\end{aligned}
$$

\section{GENERAL SOLUTION FOR INTERFACIAL SHEAR STRESS FOR CASE- 3}

The governing equation for the interfacial shear stress given in Eq. 42 is a sixth order nonhomogeneous ordinary differential equation and can be solved in closed-form. Its general solution can have the following two forms depending on the value of parameter $\Delta$ which depends on the material and geometric properties of the adherends and adhesive:

$$
\Delta=\alpha_{6}^{3}+\alpha_{7}^{2}
$$




$$
\begin{gathered}
\tau(x)=\left\{\begin{array}{c}
B_{1} e^{\psi_{1} x}+B_{2} e^{-\psi_{1} x}+e^{-\psi_{2} x}\left(B_{3} \cos \left(\psi_{3} x\right)+B_{4} \sin \left(\psi_{3} x\right)\right)+ \\
+e^{\psi_{2} x}\left(B_{5} \cos \left(\psi_{3} x\right)+B_{6} \sin \left(\psi_{3} x\right)\right)+\alpha_{15} V_{T}
\end{array}\right\} \quad \text { for } \Delta \geq 0 \\
\tau(x)=B_{7} e^{\psi_{4} x}+B_{8} e^{-\psi_{4} x}+B_{9} e^{\psi_{5} x}+B_{10} e^{-\psi_{5} x}+B_{11} e^{\psi_{6} x}+B_{12} e^{-\psi_{6} x}+\alpha_{17} V_{T} \text { for } \Delta<0
\end{gathered}
$$

where $B_{1}$ to $B_{12}$ are the constants of integration which can be determined from appropriate boundary conditions in Eq. 43. The expressions for $\alpha_{6}, \alpha_{7}, \psi_{1}$ to $\psi_{6}$ and other terms are given in Appendix A.

\section{Determination of constants $B_{1}$ to $B_{12}$}

The first three derivatives of Eq. 45 w.r.t. $x$ are:

$$
\begin{gathered}
\frac{d \tau(x)}{d x}=\left\{\begin{array}{l}
\psi_{1}\left[B_{1} e^{\psi_{1} x}-B_{2} e^{-\psi_{1} x}\right]+ \\
+e^{-\psi_{2} x}\left[-\left(\psi_{3} B_{3}+\psi_{2} B_{4}\right) \sin \left(\psi_{3} x\right)+\left(\psi_{3} B_{4}-\psi_{2} B_{3}\right) \cos \left(\psi_{3} x\right)\right]+ \\
+e^{\psi_{2} x}\left[\left(\psi_{2} B_{6}-\psi_{3} B_{5}\right) \sin \left(\psi_{3} x\right)+\left(\psi_{3} B_{6}+\psi_{2} B_{5}\right) \cos \left(\psi_{3} x\right)\right]
\end{array}\right\} \\
\frac{d^{2} \tau(x)}{d x^{2}}=\left\{\begin{array}{l}
\psi_{1}^{2}\left(B_{1} e^{\psi_{1} x}+B_{2} e^{-\psi_{1} x}\right)+e^{-\psi_{2} x}\left(\begin{array}{l}
{\left[\left(\psi_{2}^{2}-\psi_{3}^{2}\right) B_{4}+2 \psi_{2} \psi_{3} B_{3}\right] \sin \left(\psi_{3} x\right)+} \\
+\left[\left(\psi_{2}^{2}-\psi_{3}^{2}\right) B_{3}-2 \psi_{2} \psi_{3} B_{4}\right] \cos \left(\psi_{3} x\right)
\end{array}\right)+ \\
+e^{\psi_{2} x}\left(\left[\left(\psi_{2}^{2}-\psi_{3}^{2}\right) B_{6}-2 \psi_{2} \psi_{3} B_{5}\right] \sin \left(\psi_{3} x\right)+\left[\left(\psi_{2}^{2}-\psi_{3}^{2}\right) B_{5}+2 \psi_{2} \psi_{3} B_{6}\right] \cos \left(\psi_{3} x\right)\right)
\end{array}\right) \\
\frac{d^{3} \tau(x)}{d x^{3}}=\left\{\begin{array}{l}
\psi_{1}^{3}\left(B_{1} e^{\psi_{1} x}-B_{2} e^{-\psi_{1} x}\right)-e^{-\psi_{2} x}\left(\begin{array}{l}
{\left[\left(3 \psi_{2}^{2}-\psi_{3}^{2}\right) \psi_{3} \sin \left(\psi_{3} x\right)-\left(3 \psi_{3}^{2}-\psi_{2}^{2}\right) \psi_{2} \cos \left(\psi_{3} x\right)\right] B_{3}+} \\
-\left[\left(3 \psi_{3}^{2}-\psi_{2}^{2}\right) \psi_{2} \sin \left(\psi_{3} x\right)+\left(3 \psi_{2}^{2}-\psi_{3}^{2}\right) \psi_{3} \cos \left(\psi_{3} x\right)\right] B_{4}
\end{array}\right) \\
-e^{\psi_{2} x}\left(\begin{array}{l}
\left.\left[\left(3 \psi_{2}^{2}-\psi_{3}^{2}\right) \psi_{3} \sin \left(\psi_{3} x\right)+\left(3 \psi_{3}^{2}-\psi_{2}^{2}\right) \psi_{2} \cos \left(\psi_{3} x\right)\right] B_{5}+\right) \\
+\left[\left(3 \psi_{3}^{2}-\psi_{2}^{2}\right) \psi_{2} \sin \left(\psi_{3} x\right)-\left(3 \psi_{2}^{2}-\psi_{3}^{2}\right) \psi_{3} \cos \left(\psi_{3} x\right)\right] B_{6}
\end{array}\right)
\end{array}\right\}
\end{gathered}
$$

Differentiating Eq. 32 w.r.t. $x$ and substituting Eqs 17, 18 and 24 into the resulting equation gives

$$
\frac{d^{2} \tau(x)}{d x^{2}}=\frac{G_{a}}{E_{1}}\left[-m_{2} V_{T}+m_{3} b_{2} \tau(x)\right]-\alpha_{1} \frac{d \sigma(x)}{d x}
$$

Differentiating Eq. 50 w.r.t. $x$ gives

$$
\frac{d^{3} \tau(x)}{d x^{3}}=\frac{G_{a}}{E_{1}} m_{3} b_{2} \frac{d \tau(x)}{d x}-\alpha_{1} \frac{d^{2} \sigma(x)}{d x^{2}}
$$

Applying Eqs $43 \mathrm{a}-43 \mathrm{~d}$ and Eqs $43 \mathrm{~g}-43 \mathrm{j}$ respectively to Eq. 32 provide

$$
\begin{aligned}
& \left.\frac{d \tau(x)}{d x}\right|_{x=0}=\frac{G_{a}}{E_{1}}\left[-r_{1} M_{1}(0)+r_{2} M_{p l}-\left(r_{3}+r_{4}\right) N_{p l}+r_{3} N_{p r}\right]-\alpha_{1} \sigma(0) \\
& \left.\frac{d \tau(x)}{d x}\right|_{x=L_{p}}=\frac{G_{a}}{E_{1}}\left[-r_{1} M_{1}\left(L_{p}\right)+r_{2} M_{p l}-r_{4} N_{p r}\right]-\alpha_{1} \sigma\left(L_{p}\right)
\end{aligned}
$$

Setting $x=0$ and $x=L_{\mathrm{p}}$ respectively in Eq. 47 and equating the results with Eqs 52 and 53 respectively yield

$$
\psi_{1}\left(B_{1}-B_{2}\right)-\psi_{2}\left(B_{3}-B_{5}\right)+\psi_{3}\left(B_{4}+B_{6}\right)=c_{1}
$$




$$
m_{9} B_{1}-m_{10} B_{2}-m_{11} B_{3}+m_{12} B_{4}+m_{13} B_{5}+m_{14} B_{6}=c_{4}
$$

Substituting Eq. 45 into Eq. 50, equating the result with Eq. 48 and setting $x=0$ and $x=L_{\mathrm{p}}$ respectively give

$$
\begin{aligned}
& m_{4}\left(B_{1}+B_{2}\right)+m_{5}\left(B_{3}+B_{5}\right)-2 \psi_{2} \psi_{3}\left(B_{4}-B_{6}\right)=c_{2} \\
& m_{15} B_{1}+m_{16} B_{2}+m_{17} B_{3}+m_{18} B_{4}+m_{19} B_{5}+m_{20} B_{6}=c_{5}
\end{aligned}
$$

Substituting Eq. 47 into Eq. 51, equating the result with Eq. 49 and setting $x=0$ and $x=L_{\mathrm{p}}$ respectively yield

$$
\begin{aligned}
& m_{6}\left(B_{1}-B_{2}\right)+m_{7}\left(B_{3}-B_{5}\right)+m_{8}\left(B_{4}+B_{6}\right)=c_{3} \\
& m_{21} B_{1}-m_{22} B_{2}-m_{23} B_{3}+m_{24} B_{4}-m_{25} B_{5}-m_{26} B_{6}=c_{6}
\end{aligned}
$$

Eqs 54-59 form a system of simultaneous equations as given below from which the integration constants $B_{1}$ to $B_{6}$ are determined:

$$
\left[\begin{array}{llllll}
\psi_{1} & -\psi_{1} & -\psi_{2} & \psi_{3} & \psi_{2} & \psi_{3} \\
m_{4} & m_{4} & m_{5} & -2 \psi_{2} \psi_{3} & m_{5} & 2 \psi_{2} \psi_{3} \\
m_{6} & -m_{6} & m_{7} & m_{8} & -m_{7} & m_{8} \\
m_{9} & -m_{10} & -m_{11} & m_{12} & m_{13} & m_{14} \\
m_{15} & m_{16} & m_{17} & m_{18} & m_{19} & m_{20} \\
m_{21} & -m_{22} & -m_{23} & m_{24} & -m_{25} & -m_{26}
\end{array}\right]\left\{\begin{array}{l}
B_{1} \\
B_{2} \\
B_{3} \\
B_{4} \\
B_{5} \\
B_{6}
\end{array}\right\}=\left\{\begin{array}{l}
c_{1} \\
c_{2} \\
c_{3} \\
c_{4} \\
c_{5} \\
c_{6}
\end{array}\right\}
$$

Adopting a similar procedure for Eq. 46 in consideration with Eqs 50-53 provides the following system of simultaneous equations from which the constants $B_{7}$ to $B_{12}$ can be determined:

$$
\left[\begin{array}{llllll}
\psi_{4} & -\psi_{4} & \psi_{5} & -\psi_{5} & \psi_{6} & -\psi_{6} \\
p_{1} & p_{1} & p_{2} & p_{2} & p_{3} & p_{3} \\
\psi_{4} p_{1} & -\psi_{4} p_{1} & \psi_{5} p_{2} & -\psi_{5} p_{2} & \psi_{6} p_{3} & -\psi_{6} p_{3} \\
p_{4} & -p_{5} & p_{6} & -p_{7} & p_{8} & -p_{9} \\
p_{10} & p_{11} & p_{12} & p_{13} & p_{14} & p_{15} \\
\psi_{4} p_{10} & -\psi_{4} p_{11} & \psi_{5} p_{12} & -\psi_{5} p_{13} & \psi_{6} p_{14} & -\psi_{6} p_{15}
\end{array}\right]\left\{\begin{array}{c}
B_{7} \\
B_{8} \\
B_{9} \\
B_{10} \\
B_{11} \\
B_{12}
\end{array}\right\}=\left\{\begin{array}{c}
c_{1} \\
c_{2 m} \\
c_{3} \\
c_{4} \\
c_{5 m} \\
c_{6}
\end{array}\right\}
$$

Eqs 60 and 61 apply for all cases within the whole bonded length of the plate. When only the interfacial stress near the plate end at $x=0$ is concerned, the positive exponential terms in Eqs 45 and 46 can be neglected for almost all practical plated beams so that $B_{1}=B_{5}=B_{6}=B_{7}=B_{9}$ $=B_{11}=0$. This results in a simplified general solution from Eqs 45-46 as given by

$$
\begin{array}{ll}
\tau(x)=B_{2} e^{-\psi_{1} x}+e^{-\psi_{2} x}\left(B_{3} \cos \left(\psi_{3} x\right)+B_{4} \sin \left(\psi_{3} x\right)\right)+\alpha_{15} V_{T} & \text { for } \Delta \geq 0 \\
\tau(x)=B_{8} e^{-\psi_{4} x}+B_{10} e^{-\psi_{5} x}+B_{12} e^{-\psi_{6} x}+\alpha_{17} V_{T} & \text { for } \Delta<0
\end{array}
$$

This reduced solution can also be used to obtain the interfacial shear stress at the other plate end $(x=L)$ by changing the horizontal coordinate so that it originates from that end. The coefficients in Eq. 62 can be obtained from the first three rows in Eqs 60 and 61 as

$$
B_{2}=\frac{1}{m_{6}}\left(m_{7} B_{3}+m_{8} B_{4}-c_{3}\right)
$$




$$
\begin{aligned}
& B_{3}=\frac{1}{m_{27}}\left(c_{7}-m_{28} B_{4}\right) \\
& B_{4}=\frac{m_{29} c_{7}-m_{27} c_{8}}{m_{28} m_{29}-m_{27} m_{30}} \\
& B_{8}=\frac{-1}{\psi_{4} p_{1}}\left(\psi_{5} p_{2} B_{10}+\psi_{6} p_{3} B_{12}+c_{3}\right) \\
& B_{10}=\frac{1}{p_{16}}\left(c_{9}-p_{17} B_{12}\right) \\
& B_{12}=\frac{p_{18} c_{9}-p_{16} c_{10}}{p_{17} p_{18}-p_{16} p_{19}}
\end{aligned}
$$

The elements of the matrices in Eqs 60 and 61 and additional parameters in Eq. 63 are given in Appendix A.

\section{GENERAL SOLUTION FOR INTERFACIAL NORMAL STRESS FOR CASE-3}

The governing equation for the interfacial normal stress given in Eq. 40 is a fourth order non homogeneous ordinary differential equation. Its general solution can have the following three forms depending on the value of $\delta$ which is affected by the material and geometric properties of adherends and adhesive:

$$
\begin{gathered}
\delta=4 \beta_{2}-\beta_{1}^{2} \\
\sigma(x)=e^{-\eta_{1} x}\left[C_{1} \cos \left(\eta_{2} x\right)+C_{2} \sin \left(\eta_{2} x\right)\right]+e^{\eta_{1} x}\left[C_{11} \cos \left(\eta_{2} x\right)+C_{21} \sin \left(\eta_{2} x\right)\right]-n_{3} \frac{d \tau(x)}{d x} \text { for } \delta>0 \\
\sigma(x)=C_{3} e^{-\eta_{3} x}+C_{4} e^{-\eta_{4} x}+C_{31} e^{\eta_{3} x}+C_{41} e^{\eta_{4} x}+n_{8} \frac{d \tau(x)}{d x}+n_{9} \frac{d^{3} \tau(x)}{d x^{3}} \text { for } \delta<0 \\
\sigma(x)=\left[C_{5}+C_{6} x\right] e^{-\eta_{5} x}+\left[C_{51}+C_{61} x\right] e^{\eta_{5} x} \text { for } \delta=0
\end{gathered}
$$

where $C_{1}$ to $C_{6}$ and $C_{11}$ to $C_{61}$ are constants of integration to be determined from appropriate boundary conditions listed in Eq. 43. The expressions for $n_{3}$ to $n_{9}$ and $\eta_{1}$ to $\eta_{5}$ are given in Appendix B. Because $\sigma(x) \rightarrow 0$ for large values of $x, C_{11}$ to $C_{61}=0$ and Eqs $65-67$ reduce to

$$
\begin{aligned}
& \sigma(x)=e^{-\eta_{1} x}\left[C_{1} \cos \left(\eta_{2} x\right)+C_{2} \sin \left(\eta_{2} x\right)\right]-n_{3} \frac{d \tau(x)}{d x} \text { for } \delta>0 \\
& \sigma(x)=C_{3} e^{-\eta_{3} x}+C_{4} e^{-\eta_{4} x}+n_{8} \frac{d \tau(x)}{d x}+n_{9} \frac{d^{3} \tau(x)}{d x^{3}} \text { for } \delta<0 \\
& \sigma(x)=\left[C_{5}+C_{6} x\right] e^{-\eta_{5} x} \text { for } \delta=0
\end{aligned}
$$

\section{Determination of constants $C_{1}$ to $C_{6}$}

Differentiating Eq. 34 twice w.r.t.x, substituting Eq. 35 into the resulting expression and then applying the boundary condition of Eqs $43 \mathrm{a}-\mathrm{b}$ gives

$$
\left.\frac{d^{2} \sigma(x)}{d x^{2}}\right|_{x=0}=\frac{E_{a}}{t_{a} E_{2} I_{2}}\left[R_{b} M_{1}(0)+M_{p l}\right]+\left.\beta_{1} \sigma(x)\right|_{x=0}
$$

Setting $x=0$ in Eq. 68 and substituting in Eq. 71 gives 


$$
\left.\frac{d^{2} \sigma(x)}{d x^{2}}\right|_{x=0}=\frac{E_{a}}{t_{a} E_{2} I_{2}}\left[R_{b} M_{1}(0)+M_{p l}\right]+\beta_{1} C_{1}-\left.\beta_{1} n_{3} \frac{d \tau(x)}{d x}\right|_{x=0}
$$

Differentiating Eq. 68 twice w.r.t. $x$ and setting $x=0$ into the resulting equation gives

$$
\left.\frac{d^{2} \sigma(x)}{d x^{2}}\right|_{x=0}=\left(\eta_{1}^{2}-\eta_{2}^{2}\right) C_{1}-2 \eta_{1} \eta_{2} C_{2}-\left.n_{3} \frac{d^{3} \tau(x)}{d x^{3}}\right|_{x=0}
$$

From Eqs 72 and 73,

$$
\left(\eta_{1}^{2}-\eta_{2}^{2}-\beta_{1}\right) C_{1}-2 \eta_{1} \eta_{2} C_{2}=\frac{E_{a}}{t_{a} E_{2} I_{2}}\left[R_{b} M_{1}(0)+M_{p l}\right]-\left.n_{3}\left(\beta_{1} \frac{d \tau(x)}{d x}-\frac{d^{3} \tau(x)}{d x^{3}}\right)\right|_{x=0}
$$

Differentiating Eq. 34 thrice w.r.t.x, substituting Eq. 38 into the resulting expression and then applying the boundary condition of Eq. 43e-f gives

$$
\left.\frac{d^{3} \sigma(x)}{d x^{3}}\right|_{x=0}=\frac{E_{a}}{t_{a} E_{1} I_{1}} V_{T m}-n_{2 m} \tau(0)+\left.\beta_{1} \frac{d \sigma(x)}{d x}\right|_{x=0}
$$

where

$$
V_{T m}=V_{T}+\left(\frac{1+R_{b}}{R_{b}}\right) V_{p l}
$$

Differentiating Eq. 68 once w.r.t. $x$, setting $x=0$ and substituting the result into Eq. 75 gives

$$
\left.\frac{d^{3} \sigma(x)}{d x^{3}}\right|_{x=0}=\frac{E_{a}}{t_{a} E_{1} I_{1}} V_{T m}-n_{2 m} \tau(0)-\beta_{1} \eta_{1} C_{1}+\beta_{1} \eta_{2} C_{2}-\left.\beta_{1} n_{3} \frac{d^{2} \tau(x)}{d x^{2}}\right|_{x=0}
$$

Differentiating Eq. 68 thrice w.r.t. $x$ and setting $x=0$ gives

$$
\left.\frac{d^{3} \sigma(x)}{d x^{3}}\right|_{x=0}=\left[2 \eta_{1} \eta_{2}^{2}-\eta_{1}\left(\eta_{1}^{2}-\eta_{2}^{2}\right)\right] C_{1}+\left[2 \eta_{1}^{2} \eta_{2}+\eta_{2}\left(\eta_{1}^{2}-\eta_{2}^{2}\right)\right] C_{2}-\left.n_{3} \frac{d^{4} \tau(x)}{d x^{4}}\right|_{x=0}
$$

From Eqs 76 and 77,

$$
\left(3 \eta_{1} \eta_{2}^{2}-\eta_{1}^{3}+\eta_{1} \beta_{1}\right) C_{1}+\left(3 \eta_{1}^{2} \eta_{2}-\eta_{2}^{3}-\eta_{2} \beta_{1}\right) C_{2}=\frac{E_{a} V_{T m}}{t_{a} E_{1} I_{1}}-n_{2 m} \tau(0)-n_{3}\left(\beta_{1} \frac{d^{2} \tau(0)}{d x^{2}}-\frac{d^{4} \tau(0)}{d x^{4}}\right)
$$

$C_{1}$ and $C_{2}$ are obtained from Eqs 74 and 78 as

$$
\begin{aligned}
& C_{1}=\frac{E_{a}}{t_{a} E_{2} I_{2}}\left[R_{b}\left(n_{4} V_{T m}+n_{5} M_{1}(0)\right)+n_{5} M_{p l}\right]-n_{2 m} n_{4} \tau(0) \\
& \quad-n_{3} n_{5}\left(\beta_{1} \frac{d \tau(0)}{d x}-\frac{d^{3} \tau(0)}{d x^{3}}\right)-n_{3} n_{4}\left(\beta_{1} \frac{d^{2} \tau(0)}{d x^{2}}-\frac{d^{4} \tau(0)}{\left.d x^{4}\right)}\right. \\
& C_{2}=\frac{E_{a}}{t_{a} E_{2} I_{2}}\left[R_{b}\left(n_{6} V_{T m}-n_{6} n_{7} M_{1}(0)\right)-n_{6} n_{7} M_{p l}\right]-n_{2 m} n_{6} \tau(0) \\
& +n_{3} n_{6} n_{7}\left(\beta_{1} \frac{d \tau(0)}{d x}-\frac{d^{3} \tau(0)}{d x^{3}}\right)-n_{3} n_{6}\left(\beta_{1} \frac{d^{2} \tau(0)}{d x^{2}}-\frac{d^{4} \tau(0)}{d x^{4}}\right)
\end{aligned}
$$

Adopting a similar procedure individually to determine the coefficients for Eqs 69 and 70 in consideration of Eqs 71 and 75 provides the following expressions for constants $C_{3}-C_{6}$. 


$$
\begin{aligned}
& C_{3}=\frac{E_{a} n_{10}}{t_{a} E_{2} I_{2}}\left(R_{b}\left[\frac{V_{T m}}{\eta_{4}}+M_{1}(0)\right]+M_{p l}\right)-\frac{n_{2 m} n_{10}}{\eta_{4}} \tau(0)+ \\
& +n_{8} n_{10} \beta_{1}\left(\frac{d \tau(0)}{d x}+\frac{1}{\eta_{4}} \frac{d^{2} \tau(0)}{d x^{2}}\right)+\left(n_{9} \beta_{1}-n_{8}\right) n_{10}\left(\frac{d^{3} \tau(0)}{d x^{3}}+\frac{1}{\eta_{4}} \frac{d^{4} \tau(0)}{d x^{4}}\right) \\
& C_{4}=\frac{E_{a} n_{11}}{t_{a} E_{2} I_{2}}\left(R_{b}\left[\frac{V_{T m}}{\eta_{3}}+M_{1}(0)\right]+M_{p l}\right)-\frac{n_{2 m} n_{11}}{\eta_{3}} \tau(0)+ \\
& +n_{8} n_{11} \beta_{1}\left(\frac{d \tau(0)}{d x}+\frac{1}{\eta_{3}} \frac{d^{2} \tau(0)}{d x^{2}}\right)+\left(n_{9} \beta_{1}-n_{8}\right) n_{11}\left(\frac{d^{3} \tau(0)}{d x^{3}}+\frac{1}{\eta_{3}} \frac{d^{4} \tau(0)}{d x^{4}}\right) \\
& C_{5}=\frac{E_{a} n_{13}}{t_{a} E_{2} I_{2}}\left(R_{b}\left[n_{12} V_{T m}+M_{1}(0)\right]+M_{p l}\right)-n_{2 m} n_{12} n_{13} \tau(0) \\
& C_{6}=\frac{\left(\eta_{5}^{2}-\beta_{1}\right)}{2 \eta_{5}} C_{5}-\frac{E_{a}}{2 \eta_{5} t_{a} E_{2} I_{2}}\left(R_{b} M_{1}(0)+M_{p l}\right)
\end{aligned}
$$

The expressions for $n_{2 \mathrm{~m}}, n_{3}-n_{13}$ are given in Appendix B.

\section{SOLUTION FOR GENERAL LOADING (CASE-1)}

The solutions from Case- 2 and 3 are combined to get the solution for the original problem in

Case-1. The interfacial shear stress is given by the combination of Eqs 15 and 45 or 46 as:

$$
\begin{array}{ll}
\tau(x, y)=m_{c}(y) V_{T c}(x)+B_{2} e^{-\psi_{1} x}+e^{-\psi_{2} x}\left[B_{3} \cos \left(\psi_{3} x\right)+B_{4} \sin \left(\psi_{3} x\right)\right]+\alpha_{15} V_{T} & \text { for } \Delta \geq 0 \\
\tau(x, y)=m_{c}(y) V_{T c}(x)+B_{8} e^{-\psi_{4} x}+B_{10} e^{-\psi_{5} x}+B_{12} e^{-\psi_{6} x}+\alpha_{17} V_{T} & \text { for } \Delta<0
\end{array}
$$

The interfacial normal stress is given by Eq. 68 or 69 or 70 depending on $\delta$ in Eq. 64 .

\section{COMPARISON OF INTERFACIAL STRESS SOLUTIONS}

\section{Example beams, reference solutions and FEA}

A comparison of the predicted interfacial shear and normal stresses from the closed-form solutions reviewed earlier is conducted in this section. A simply supported RC beam of rectangular cross section plated respectively with carbon fibre reinforced polymer (CFRP) composite and glass fibre reinforced polymer (GFRP) composite are taken as illustrative examples. The geometric and material properties of the example beam listed in Table 1 are taken from Smith \& Teng [8]. Three different loading examples are considered: an UDL as in Fig. 4a, a mid-point load as in Fig. 4b and a complex loading arrangement as in Fig. 4c.

Interfacial shear and normal stresses are compared from results computed using the present solution, reference solutions ignoring the shear deformation effect and previous solutions with the shear deformation effect included. Due to their accuracy and simplicity, the closed-form solutions of Smith and Teng [8] and Narayanamurthy et al. [20] are used as reference solutions for all solutions which do not include the effect of shear deformation. The present solution for the UDL loading is also compared with finite element analysis (FEA) results based on Euler-Bernoulli and Timoshenko beam elements and with previous three approximate solutions which include the effect of shear deformation in adherends (Abdelouahed [17]; Yang and $\mathrm{Wu}$ [18] and Narayanamurthy et al. [23]). 
The FEA was carried out for the example plated beams under UDL in ANSYS 10.0 [30]. The plated beam was modelled as a beam-spring-beam (B-S-B) model as in Zhang and Teng [31]. The beam and plate were modelled as beam elements using BEAM44, a uniaxial beam element which can function either as an Euler-Bernoulli or as a Timoshenko beam. The adhesive was modelled using COMBIN39, a non-linear unidirectional spring element which can be made to act as either a normal or shear elastic spring. Both normal and shear springs were used to model the adhesive and their stiffness represented that of the adhesive layer. This implies that the interfacial shear and normal stresses are constant through the thickness of the adhesive layer which is in agreement with the assumption in all classical solutions including the present. This B-S-B model complies with the assumption of treating the adherends as two Euler-Bernoulli beams as employed in the reference solutions and as two Timoshenko beams as considered in the present solution. The beam elements were located along the lower edge of the beam and the upper edge of the plate by appropriately offsetting the reference nodes in beam elements so that they can be connected directly by spring elements. An element size of $1 \mathrm{~mm}$ was used in the model as recommended in Zhang and Teng [31] based on their convergence study. The interfacial stresses are converted from discrete elastic spring forces by dividing the spring force by the effective width (area) represented by the springs. This effective width equals the centre to centre spacing of two adjacent elements on the two sides of the spring for all springs except for the end spring for which the effective width equals half width of the end element.

\section{Example beam under UDL}

The peak interfacial stresses from various closed-form solutions considered here and from FEA for both CFRP and GFRP plated beams under the UDL are provided in Table 2, while the distributions of the interfacial stresses near the plate end for the CFRP plated beam under the UDL are shown in Figs 5a-d. The peak interfacial shear stresses from the present and the reference solutions are very slightly higher than those from the FEA with and without shear deformation. Their differences reduce gradually away from the plate end and the predictions of all solutions are almost exactly the same $20 \mathrm{~mm}$ away from the plate end. The peak interfacial shear stress from the present solution (which includes the effect of shear deformation) is about $2.4 \%$ smaller than that from the reference solutions (which do not include the effect of shear deformation) for both example beams (Fig. 5a and Table 2). Similarly the results from the FEA with shear deformation are smaller than those from FEA without shear deformation by about $2.2 \%$ and $2.7 \%$ for CFRP and GFRP plated beams respectively (Fig. 5a and Table 2). It is seen from Fig. 5a that the interfacial shear stress is not affected by the shear deformation of the adherends in any significant way.

All three previous approximate solutions that consider the effect of shear deformation predict a reduction in the peak interfacial shear stress compared with the reference solution (Fig. 5b and Table 2), but the two solutions that adopt an approximate shear stress distribution in the adherends (Abdelouahed [17] and Narayanamurthy et al. [23]) predict huge reductions in peak interfacial shear stress which does not conform to either the present solution or to the FEA 'with shear deformation' solution.

The interfacial normal stress predicted by the present solution is in very close agreement with the FEA 'with shear deformation' prediction (Fig. 5c). The two reference solutions are also in very close agreement with the FEA 'without shear deformation' prediction, except for a slightly lower peak value for the latter (Fig. 5c). Shear deformation in the adherends increases the peak interfacial normal stress. The present solution predicts stresses $11.1 \%$ and $3.9 \%$ higher than the reference solutions for the CFRP and GFRP plated beams respectively. 
Among the FEA results, FEA 'with shear deformation' predicts $20.9 \%$ and $13.7 \%$ higher than FEA 'without shear deformation' respectively for the different plating materials.

Among the three previous approximate solutions $[17,18,23]$ that considered the effect of shear deformation, Abdelouahed [17] does not explicitly include the effect of adherend shear deformation on the interfacial normal stress term but its prediction does deviate slightly from that of the FEA 'without shear deformation' because of the influence of its peak shear stress. Yang and Wu's [18] prediction which included the effect of adherend's shear deformation only in interfacial shear stress is almost identical to the FEA 'without shear deformation' solution and to the reference solutions. Thus these two solutions [17,18] are not in good agreement with FEA 'with shear deformation' solution. Narayanamurthy et al.'s [23] prediction is in good agreement with the FEA 'with shear deformation' solution except within about $2-3 \mathrm{~mm}$ from the plate end within which the prediction is lower than the latter.

Figures 6 and 7 illustrate the effect of shear deformation on the peak interfacial stresses for various elastic modulus of adhesive and plate thickness for the CFRP plated reference beam under UDL. The vertical coordinate represents the difference between the present solution and the reference solution of Narayanamurthy et al.'s [23] with respect to the reference solution as a percentage, thus a positive value represents an increase in peak interfacial stress. Within the range of the parameters shown, the effect of the shear deformation on peak interfacial shear stress in general is insignificant, but it is significant and detrimental to the peak interfacial normal stress. The effect on the peak interfacial shear stress is generally advantageous because it tends to reduce the peak shear stress for increasing value of adhesive elastic modulus and decreasing value of length-to-thickness ratio of plate, but usually only less than 2\% (Figs. 6 and 7). The effect on the peak interfacial normal stress generally increases with a reducing elastic modulus of the adhesive and increasing plate thickness. This effect increases the peak interfacial normal stress between $1 \%$ to $18 \%$ as the elastic modulus of adhesive decreases from $10 \mathrm{GPa}$ to $0.5 \mathrm{GPa}$ (Fig. 6) and between $9.5 \%$ to $24.5 \%$ as the length-to-thickness ratio of plate decreases from 9500 to 500 (Fig. 7). For a safer prediction of interfacial stresses, it is recommended to use the present solution to predict the interfacial normal stress which is influenced significantly by the effect of adherend's shear deformation; while either the present or the reference solutions can be used to predict the interfacial shear stress.

\section{Example beam under other loading}

The general conclusions drawn above on the effect of shear deformation also apply for the CFRP and GFRP plated beams under a mid point load (Fig. 4b) and a complex loading arrangement (Fig. 4c), with small variations in value. Taking Narayanamurthy et al.'s [20] solution as the reference, the present solution predicts $2.7 \%$ and $2.6 \%$ lower peak shear stress and $4.6 \%$ and $2.8 \%$ higher peak normal stress respectively for loading arrangements in Fig. $4 \mathrm{~b}$ and Fig. 4c for the GFRP plated beam. Similarly, the present prediction for peak interfacial shear stress in the CFRP plated beam is $2.5 \%$ lower for both loading arrangements and peak normal stresses are $12 \%$ and $10 \%$ respectively greater for loading arrangements in Fig. $4 \mathrm{~b}$ and Fig. 4c. This shows the difference in peak interfacial shear stress between present and reference solutions is almost the same for both CFRP and GFRP plated beams in all loading arrangements. The difference is also very close to that between the FEA with and without shear deformation predictions. The increase in the peak normal stress is much higher for the CFRP plated beam compared to the GFRP plated beam due to the difference in flexural stiffness. The loading examples provided in Figs $4 \mathrm{a}-\mathrm{c}$ and their interfacial stress predictions discussed above illustrate the applicability of the present improved closed-form solution for 
interfacial stresses accounting the shear deformation of adherends for arbitrary loading and any linear elastic adherends.

\section{CONCLUSIONS}

Debonding failures observed in plated beams are attributable to the concentration of interfacial stresses at the ends of bonded plates. It is important to quantify these interfacial stresses correctly for the safe design of plated beams, taking account of all relevant deformations, but most previous solutions have neglected the effect of shear deformations in adherends due to the complexity in the formulation. This paper has presented a closed-form rigorous theoretical solution to simultaneously include the effect of axial, bending and shear deformations in adherends to quantify these interfacial shear and normal stresses in plated beams. The solution has been developed by treating plate and beam as two Timoshenko beams, and is applicable to beams of any prismatic cross section under any loading arrangement with a plate bonded symmetrically or asymmetrically. A comparison shows that the solution is in close agreement in both interfacial shear and normal stresses with those obtained by the finite element analysis. This study has shown that the effect of the shear deformation of the adherends is not significant for the interfacial shear stress, but is significant for the interfacial normal stress.

\section{APPENDIX A. TERMS IN THE SOLUTION OF INTERFACIAL SHEAR STRESS} (Eqs 44-63f)

$$
\begin{aligned}
& \alpha_{6}=\frac{3 \alpha_{3}-\alpha_{2}^{2}}{9} \\
& \alpha_{7}=\frac{-9 \alpha_{2} \alpha_{3}+27 \alpha_{4}+2 \alpha_{2}^{3}}{54} \\
& \alpha_{8}=\sqrt[3]{\alpha_{7}+\sqrt{\Delta}} \\
& \alpha_{9}=\sqrt[3]{\alpha_{7}-\sqrt{\Delta}} \\
& \alpha_{10}=\frac{\alpha_{2}}{3}+\alpha_{8}+\alpha_{9} \\
& \alpha_{11}=\frac{\alpha_{2}}{3}-\frac{\left(\alpha_{8}+\alpha_{9}\right)}{2} \\
& \alpha_{12}=\frac{\sqrt{3}}{2}\left(\alpha_{8}-\alpha_{9}\right) \\
& \alpha_{13}=\psi_{1}^{2}\left[\left(\psi_{1}+\psi_{2}\right)^{2}+\psi_{3}^{2}\right]\left[\left(\psi_{1}-\psi_{2}\right)^{2}+\psi_{3}^{2}\right] \\
& \alpha_{14}=\left(\psi_{2}^{2}+\psi_{3}^{2}\right)\left[\left(\psi_{1}^{2}-\psi_{2}^{2}\right)^{2}+\psi_{3}^{4}+2 \psi_{3}^{2}\left(\psi_{1}^{2}+\psi_{2}^{2}\right)\right] \\
& \alpha_{15}=\frac{\alpha_{5}\left[\alpha_{13}\left(\psi_{1}^{2}-2 \psi_{2}^{2}+2 \psi_{3}^{2}\right)+\alpha_{14}\right]}{\alpha_{13} \alpha_{14}} \\
& \alpha_{16}=\sqrt{\alpha_{7}^{2}-\Delta} \\
& \alpha_{17}=-\frac{\alpha_{5}\left[\psi_{4}^{4}\left(\psi_{5}^{2}-\psi_{6}^{2}\right)+\psi_{5}^{4}\left(\psi_{6}^{2}-\psi_{4}^{2}\right)+\psi_{6}^{4}\left(\psi_{4}^{2}-\psi_{5}^{2}\right)\right]}{\left[\left(\psi_{4}^{2}-\psi_{5}^{2}\right)\left(\psi_{5}^{2}-\psi_{6}^{2}\right)\left(\psi_{6}^{2}-\psi_{4}^{2}\right)\left(\psi_{4}^{2} \psi_{5}^{2} \psi_{6}^{2}\right)\right]}
\end{aligned}
$$




$$
\begin{aligned}
& \theta=\frac{1}{3} \cos \left(\frac{\alpha_{7}}{\alpha_{16}}\right) \\
& \psi_{1}=\sqrt{\alpha_{10}} \\
& \psi_{2}=\sqrt{0.5\left(\sqrt{\alpha_{11}^{2}+\alpha_{12}^{2}}+\alpha_{11}\right)} \\
& \psi_{3}=\frac{\alpha_{12}}{2 \psi_{2}} \\
& \psi_{4}=\sqrt{\frac{\alpha_{2}}{3}+2 \sqrt[3]{\alpha_{16}} \cos \theta} \\
& \psi_{5}=\sqrt{\left|\frac{\alpha_{2}}{3}-\sqrt[3]{\alpha_{16}}(\cos \theta+\sqrt{3} \sin \theta)\right|} \\
& \psi_{6}=\sqrt{\left|\frac{\alpha_{2}}{3}-\sqrt[3]{\alpha_{16}}(\cos \theta-\sqrt{3} \sin \theta)\right|} \\
& m_{2}=\frac{r_{1}+r_{2} R_{b}}{1+R_{b}} \\
& m_{3}=\frac{\left(r_{1}+r_{2} R_{b}\right)\left(y_{1}+y_{2}+t_{a}\right)}{1+R_{b}}+r_{3}+r_{4} \\
& m_{4}=\psi_{1}^{2}-\frac{G_{a} m_{3} b_{2}}{E_{1}} \\
& m_{5}=\psi_{2}^{2}-\psi_{3}^{2}-\frac{G_{a} m_{3} b_{2}}{E_{1}} \\
& m_{6}=\psi_{1} m_{4} \\
& m_{7}=\psi_{2}\left(2 \psi_{3}^{2}-m_{5}\right) \\
& m_{8}=\psi_{3}\left(2 \psi_{2}^{2}+m_{5}\right) \\
& m_{i}=\psi_{1} e^{(-1)^{i+1} \psi_{1} L_{p}} \\
& m_{11}=e^{-\psi_{2} L_{p}}\left[\psi_{3} \sin \left(\psi_{3} L_{p}\right)+\psi_{2} \cos \left(\psi_{3} L_{p}\right)\right] \\
& m_{12}=e^{-\psi_{2} L_{p}}\left[\psi_{3} \cos \left(\psi_{3} L_{p}\right)-\psi_{2} \sin \left(\psi_{3} L_{p}\right)\right] \\
& m_{13}=e^{\psi_{2} L_{p}}\left[\psi_{2} \cos \left(\psi_{3} L_{p}\right)-\psi_{3} \sin \left(\psi_{3} L_{p}\right)\right] \\
& m_{14}=e^{\psi_{2} L_{p}}\left[\psi_{2} \sin \left(\psi_{3} L_{p}\right)+\psi_{3} \cos \left(\psi_{3} L_{p}\right)\right] \\
& m_{i}=m_{4} e^{(-1)^{i+1} \psi_{1} L_{p}} \\
& m_{17}=e^{-\psi_{2} L_{p}}\left[m_{5} \cos \left(\psi_{3} L_{p}\right)+2 \psi_{2} \psi_{3} \sin \left(\psi_{3} L_{p}\right)\right] \\
& m_{18}=e^{-\psi_{2} L_{p}}\left[m_{5} \sin \left(\psi_{3} L_{p}\right)-2 \psi_{2} \psi_{3} \cos \left(\psi_{3} L_{p}\right)\right] \\
& m_{19}=e^{\psi_{2} L_{p}}\left[m_{5} \cos \left(\psi_{3} L_{p}\right)-2 \psi_{2} \psi_{3} \sin \left(\psi_{3} L_{p}\right)\right] \\
& m_{20}=e^{\psi_{2} L_{p}}\left[m_{5} \sin \left(\psi_{3} L_{p}\right)+2 \psi_{2} \psi_{3} \cos \left(\psi_{3} L_{p}\right)\right] \\
& m_{(21+i)}=\psi_{1} m_{(15+i)} \\
& m_{23}=e^{-\psi_{2} L_{p}}\left(\left(3 \psi_{2}^{2}-\psi_{3}^{2}\right) \psi_{3} \sin \left(\psi_{3} L_{p}\right)-\left(3 \psi_{3}^{2}-\psi_{2}^{2}\right) \psi_{2} \cos \left(\psi_{3} L_{p}\right)-\frac{G_{a} m_{3} b_{2} m_{11}}{E_{1}}\right) \\
& m_{24}=e^{-\psi_{2} L_{p}}\left(\left(3 \psi_{3}^{2}-\psi_{2}^{2}\right) \psi_{2} \sin \left(\psi_{3} L_{p}\right)+\left(3 \psi_{2}^{2}-\psi_{3}^{2}\right) \psi_{3} \cos \left(\psi_{3} L_{p}\right)-\frac{G_{a} m_{3} b_{2} m_{12}}{E_{1}}\right)
\end{aligned}
$$




$$
\begin{aligned}
& m_{25}=e^{\psi_{2} L_{p}}\left(\left(3 \psi_{2}^{2}-\psi_{3}^{2}\right) \psi_{3} \sin \left(\psi_{3} L_{p}\right)+\left(3 \psi_{3}^{2}-\psi_{2}^{2}\right) \psi_{2} \cos \left(\psi_{3} L_{p}\right)+\frac{G_{a} m_{3} b_{2} m_{13}}{E_{1}}\right) \\
& m_{26}=e^{\psi_{2} L_{p}}\left(\left(3 \psi_{3}^{2}-\psi_{2}^{2}\right) \psi_{2} \sin \left(\psi_{3} L_{p}\right)-\left(3 \psi_{2}^{2}-\psi_{3}^{2}\right) \psi_{3} \cos \left(\psi_{3} L_{p}\right)+\frac{G_{a} m_{3} b_{2} m_{14}}{E_{1}}\right) \\
& m_{27}=-\psi_{2}-\frac{\psi_{1} m_{7}}{m_{6}} \\
& m_{28}=\psi_{3}-\frac{\psi_{1} m_{8}}{m_{6}} \\
& m_{29}=\frac{m_{4} m_{7}}{m_{6}}+m_{5} \\
& m_{30}=\frac{m_{4} m_{8}}{m_{6}}-2 \psi_{2} \psi_{3} \\
& p_{i}=\psi_{(i+3)}^{2}-\frac{G_{a} m_{3} b_{2}}{E_{1}} \\
& p_{i}=\psi_{4} e^{(-1)^{i} \psi_{4} L_{p}} \\
& p_{i}=\psi_{5} e^{(-1)^{i} \psi_{5} L_{p}} \\
& p_{i}=\psi_{6} e^{(-1)^{i} \psi_{6} L_{p}} \\
& p_{i}=p_{1} e^{(-1)^{i} \psi_{4} L_{p}} \\
& p_{i}=p_{2} e^{(-1)^{i} \psi_{5} L_{p}} \\
& p_{i}=p_{3} e^{(-1)^{i} \psi_{6} L_{p}} \\
& p_{16}=-\frac{\psi_{5}}{p_{1}}\left(p_{1}-p_{2}\right) \\
& p_{17}=-\frac{\psi_{6}}{p_{1}}\left(p_{1}-p_{3}\right) \\
& p_{18}=\frac{p_{2}}{\psi_{4}}\left(\psi_{4}-\psi_{5}\right) \\
& p_{19}=\frac{p_{3}}{\psi_{4}}\left(\psi_{4}-\psi_{6}\right) \\
& c_{1}=\frac{G_{a}}{E_{1}}\left[-r_{1} M_{1}(0)+r_{2} M_{p l}-\left(r_{3}+r_{4}\right) N_{p l}+r_{3} N_{p r}\right]-\alpha_{1} \sigma(0) \\
& c_{2}=\frac{G_{a}}{E_{1}}\left(m_{3} b_{2} \alpha_{15}-m_{2}\right) V_{T}-\alpha_{1} \sigma^{\prime}(0) \\
& c_{2 m}=\frac{G_{a}}{E_{1}}\left(m_{3} b_{2} \alpha_{17}-m_{2}\right) V_{T}-\alpha_{1} \sigma^{\prime}(0) \\
& c_{3}=-\alpha_{1} \sigma^{\prime \prime}(0) \\
& c_{4}=\frac{G_{a}}{E_{1}}\left[-r_{1} M_{1}\left(L_{p}\right)+r_{2} M_{p l}-r_{4} N_{p r}\right]-\alpha_{1} \sigma\left(L_{p}\right) \\
& c_{5}=\frac{G_{a}}{E_{1}}\left(m_{3} b_{2} \alpha_{15}-m_{2}\right) V_{T}-\alpha_{1} \sigma^{\prime}\left(L_{p}\right)
\end{aligned}
$$




$$
\begin{aligned}
& c_{5 m}=\frac{G_{a}}{E_{1}}\left(m_{3} b_{2} \alpha_{17}-m_{2}\right) V_{T}-\alpha_{1} \sigma^{\prime}\left(L_{p}\right) \\
& c_{6}=-\alpha_{1} \sigma^{\prime \prime}\left(L_{p}\right) \\
& c_{7}=c_{1}-\frac{\psi_{1} c_{3}}{m_{6}} \\
& c_{8}=c_{2}+\frac{m_{4} c_{3}}{m_{6}} \\
& c_{9}=c_{1}-\frac{c_{3}}{p_{1}} \\
& c_{10}=c_{2 m}+\frac{c_{3}}{\psi_{4}}
\end{aligned}
$$

APPENDIX B. TERMS IN THE SOLUTION OF INTERFACIAL NORMAL STRESS (Eqs 65-84)

$$
\begin{aligned}
& \eta_{1}=0.5 \sqrt{\beta_{1}+2 \sqrt{\beta_{2}}} \\
& \eta_{2}=\frac{\sqrt{\delta}}{4 \eta_{1}} \\
& \eta_{3}=\sqrt{0.5\left(\beta_{1}+\sqrt{-\delta}\right)} \\
& \eta_{4}=\sqrt{0.5\left(\beta_{1}-\sqrt{-\delta}\right)} \\
& \eta_{5}=\sqrt{0.5 \beta_{1}} \\
& n_{2 m}=\frac{E_{a} b_{2}}{t_{a}}\left(\frac{y_{1}+t_{a}}{E_{1} I_{1}}-\frac{y_{2}}{E_{2} I_{2}}\right) \\
& n_{3}=\frac{n_{2}}{\left(\eta_{1}^{2}+\eta_{2}^{2}\right)^{2}} \\
& n_{4}=\frac{\left(\eta_{1}^{2}-\eta_{2}^{2}-\beta_{1}\right)\left(3 \eta_{1}^{2} \eta_{2}-\eta_{2}^{3}-\eta_{2} \beta_{1}\right)+\left(3 \eta_{1} \eta_{2}^{2}-\eta_{1}^{3}+\eta_{1} \beta_{1}\right)\left(2 \eta_{1} \eta_{2}\right)}{n_{5}}=\frac{1-n_{4}\left(3 \eta_{1} \eta_{2}^{2}-\eta_{1}^{3}+\eta_{1} \beta_{1}\right)}{\eta_{1}^{2}-\eta_{2}^{2}-\beta_{1}} \\
& n_{6}=\frac{n_{4}\left(\eta_{1}^{2}-\eta_{2}^{2}-\beta_{1}\right)}{2 \eta_{1} \eta_{2}} \\
& n_{9}=n_{8}\left(\frac{1}{\eta_{3}^{2}}+\frac{1}{\eta_{4}^{2}}\right) \\
& n_{7}=\frac{3 \eta_{1} \eta_{2}^{2}-\eta_{1}^{3}+\eta_{1} \beta_{1}}{\eta_{1}^{2}-\eta_{2}^{2}-\beta_{1}} \\
& \eta_{3}^{2} \eta_{4}^{2} \\
& \left.\eta_{4}-\eta_{3}\right)\left(\eta_{3}^{2}-\beta_{1}\right) \\
& n_{1}
\end{aligned}
$$




$$
\begin{aligned}
& n_{11}=\frac{\eta_{3}}{\left(\eta_{3}-\eta_{4}\right)\left(\eta_{4}^{2}-\beta_{1}\right)} \\
& n_{12}=\frac{2 \eta_{5}}{3 \eta_{5}^{2}-\beta_{1}} \\
& n_{13}=\frac{3 \eta_{5}^{2}-\beta_{1}}{\left(\eta_{5}^{2}-\beta_{1}\right)^{2}}
\end{aligned}
$$




\section{REFERENCES}

[1] Vilnay O. The analysis of reinforced concrete beams strengthened by epoxy bonded steel plates. International Journal of Cement Composites and Lightweight Concrete 1988;10(2):73-78.

[2] Roberts TM. Approximate analysis of shear and normal stress concentrations in the adhesive layer of plated RC beams. The Structural Engineer 1989;67(12):229-33.

[3] Roberts TM, Haji-Kazemi H. Theoretical study of the behaviour of reinforced concrete beams strengthened by externally bonded steel plates. Proceedings of the Institution of Civil Engineers 1989;87(2):39-55.

[4] Liu Z, Zhu B. Analytical solutions for RC beams strengthened by externally bonded steel plates. Journal of Tongji University 1994;22(1):21-26.

[5] Taljsten B. Strengthening of beams by plate bonding. ASCE International Journal of Materials in Civil Engineering 1997;9(4):206-12.

[6] Malek AM, Saadatmanesh H, Ehsani MR. Prediction of failure load of RC beams strengthened with FRP plate due to stress concentration at the plate end. ACI Structural Journal 1998;95(1):142-52.

[7] Rabinovich O, Frostig Y. Closed-form high-order analysis of RC beams strengthened with FRP strips. ASCE Journal of Composites for Construction 2000;4(2):65-74.

[8] Smith ST, Teng JG. Interfacial stresses in plated beams. Engineering Structures 2001;23:857-71.

[9] Shen HS, Teng JG, Yang J. Interfacial stresses in beams and slabs bonded with thin plate. ASCE Journal of Engineering Mechanics 2001;127(4):399-406.

[10] Maalej M, Bian Y. Interfacial shear stress concentration in FRP-strengthened beams. Composite Structures 2001;54(4): 417-26.

[11] Ye JQ. Interfacial shear transfer of RC beams strengthened by bonded composite plates. Cement and Concrete Composites 2001;23(4-5): 411-417.

[12] Deng J, Lee MK, Moy SJ. Stress analysis of steel beams reinforced with a bonded CFRP plate. Composite Structures 2004;65:205-15.

[13] Yang J, Teng JG, Chen JF. A high order closed-form solution for interfacial stresses in soffit plated RC beams under arbitrary loads. ICE Proceedings: Structures and Buildings 2004;157(SB1):77-89.

[14] Yang J, Chen JF, Teng JG. Interfacial stress analysis of plated beams under symmetric mechanical and thermal loading. Construction and Building Materials 2009;23(9):297387.

[15] Stratford T, Cadei J. Elastic analysis of adhesion stresses for the design of a strengthening plate bonded to a beam. Construction and Building Materials 2006;20(12):34-45.

[16] De Lorenzis L, Teng JG, Zhang L. Interfacial stresses in curved members bonded with a thin plate. International Journal of Solids and Structures 2006;43:7501-17.

[17] Abdelouahed T. Improved theoretical solution for interfacial stresses in concrete beams strengthened with FRP plate. International Journal of Solids and Structures 2006; 43:4154-74.

[18] Yang J, Wu YF. Interfacial stresses of FRP strengthened concrete beams: Effect of shear deformation. Composite Structures 2007;80:343-51.

[19] Li LJ, Guo YC, Huang PY, Liu F, Deng J, Zhu J. Interfacial stress analysis of RC beams strengthened with hybrid CFS and GFS. Construction and Building Materials 2009;23(6): 2394-401.

[20] Narayanamurthy V, Chen JF, Cairns J. A general analytical method for the analysis of interfacial stresses in plated beams under arbitrary loading. Advances in Structural Engineering 2010;13(5):975-88. 
[21] Zhang L, Teng JG. Simple general solution for interfacial stresses in plated beams. ASCE Journal of Composites for Construction 2010;14 (4):434-42.

[22] Abdelouahed T, Hassaine DT, Benyoucef S, Adda bedia EA. Interfacial stresses in FRPplated RC beams: effect of adherend shear deformations. International Journal of Adhesion and Adhesives 2007;29 (4):343-51.

[23] Narayanamurthy V, Chen JF, Cairns J, Ananth R. Effect of shear deformation on interfacial stresses of plated beams subjected to arbitrary loading. International Journal of Adhesion and Adhesives 2011;31: 862-74.

[24] Edalati M, Irani F. Interfacial stresses in RC beams strengthened by externally bonded $\mathrm{FRP} /$ steel plates with effects of shear deformations. Journal of Composites for Construction 2012;16(1): 60-73.

[25] Delale F, Erdogan F, Aydinoglu MN. Stress in adhesively bonded joints: a closed-for solution. Journal of Composite Materials 1981;15: 249-71.

[26] Tsai MY, Oplinger DW, Morton J. Improved theoretical solutions for adhesive lap joints. International Journal of Solids and Structures 1998;35(12):1163-85.

[27] Chalkley P, Rose LRF. Variational bounds for the equivalent spring constants for bonded repairs. DSTO Aeronautical and Maritime Research Laboratory Report 1998; AR-010-644, Melbourne, Australia, pp 41.

[28] Carrera E, Ciuffreda A. A unified formulation to assess theories of multilayered plates for various bending problems. Composite Structures 2005;69: 271-93.

[29] Cui H, Koussios S, Li Y, Beukers A. Measurement of adhesive shear properties by short beam shear test based on higher order beam theory. International Journal of Adhesion and Adhesives 2013;40: 19-30.

[30] ANSYS Release 10.0, User's manual, ANSYS Inc., USA, 2005.

[31] Zhang L, Teng JG. Finite element prediction of interfacial stresses in structural members bonded with a thin plate. Engineering Structures 2010;33(2): 459-71. 


\section{NOTATION}

The following symbols are used in this paper:

$$
\begin{aligned}
& A=\text { cross sectional area of the adhesive or adherends; } \\
& b=\text { width of the adhesive or adherends; } \\
& E=\text { modulus of elasticity of the adhesive or adherends; } \\
& G=\text { shear modulus of the adhesive; } \\
& I=\text { second moment of area of the adhesive or adherends about their } \\
& \text { centroidal axis; } \\
& I_{1 c}, I_{a c}, I_{2 c}=\text { second moment of area of beam, adhesive and plate section about the } \\
& \text { centroidal axis of the composite beam section respectively; } \\
& I_{e}=\text { second moment of area of the equivalent composite beam section about } \\
& \text { its centroidal axis; } \\
& L=\text { length of the adhesive or adherends; } \\
& L_{p}=\text { length of the plate; } \\
& M=\text { bending moment in the adherends; } \\
& M(0), M\left(L_{p}\right)=\text { bending moment in plated beam at } x=0 \text { and } x=L_{p} \text { under original loading } \\
& \text { ignoring the effects of plate end loading (Case-2); } \\
& M_{1}(0), M_{1}\left(L_{p}\right)=\text { bending moment in beam at } x=0 \text { and } x=L_{p} \text { in Case- } 3 \text { loading; } \\
& M_{T}(x)=\text { total applied bending moment at any section of the plated beam; } \\
& N=\text { axial force in the adherends; } \\
& N(x)=\text { resultant axial force resisted by any section of the adherends; } \\
& Q_{e}(x, y)=\text { first moment of area of equivalent adhesive or plate section about the } \\
& \text { centroidal axis of the composite beam section; } \\
& t=\text { thickness of the adhesive or adherends; } \\
& u=\text { longitudinal displacement of the adherends; } \\
& v=\text { vertical displacement of the adherends; } \\
& V(x)=\text { shear force at any section of adherends; } \\
& V_{T c}(x)=\text { total applied shear force at any section of the composite beam; } \\
& V_{T}=\text { total shear force at any section of the plated beam in Case-3 loading; } \\
& y_{c}=\text { vertical distance from top of the beam to the centroid of the composite } \\
& \text { beam section; } \\
& y_{1}, y_{2}=\text { vertical distance from bottom of the beam and top of the plate to their } \\
& \text { respective centroids respectively; } \\
& p l, p r=\text { subscripts referring respectively to the left and right end of the plate; } \\
& 1, a, 2=\text { subscripts referring respectively to the beam, adhesive and plate; } \\
& \kappa_{i}=\text { Timoshenko's shear coefficient; } \\
& \sigma(x)=\text { interfacial normal stress at any section of the plated beam; } \\
& \tau(x)=\text { interfacial shear stress at any section of the plated beam; } \\
& \gamma_{x y}=\text { engineering shear strain at the adhesive layer; } \\
& \varepsilon_{1}(x), \varepsilon_{2}(x)=\text { longitudinal strain at bottom layer of beam and at top layer of plate } \\
& \text { respectively; } \\
& \psi_{1}-\psi_{6}=\text { roots for the governing differential equation of } \tau(x) \text { in Case-3 loading; } \\
& \eta_{1}-\eta_{5}=\text { roots for the governing differential equation of } \sigma(x) \text { in Case-3 loading; } \\
& B_{1}-B_{12}=\text { constants of integration in general solution of } \tau(x) \text { in Case-3 loading; and } \\
& C_{1}-C_{6}=\text { constants of integration in general solution of } \sigma(x) \text { in Case-3 loading. }
\end{aligned}
$$




\section{FIGURES}

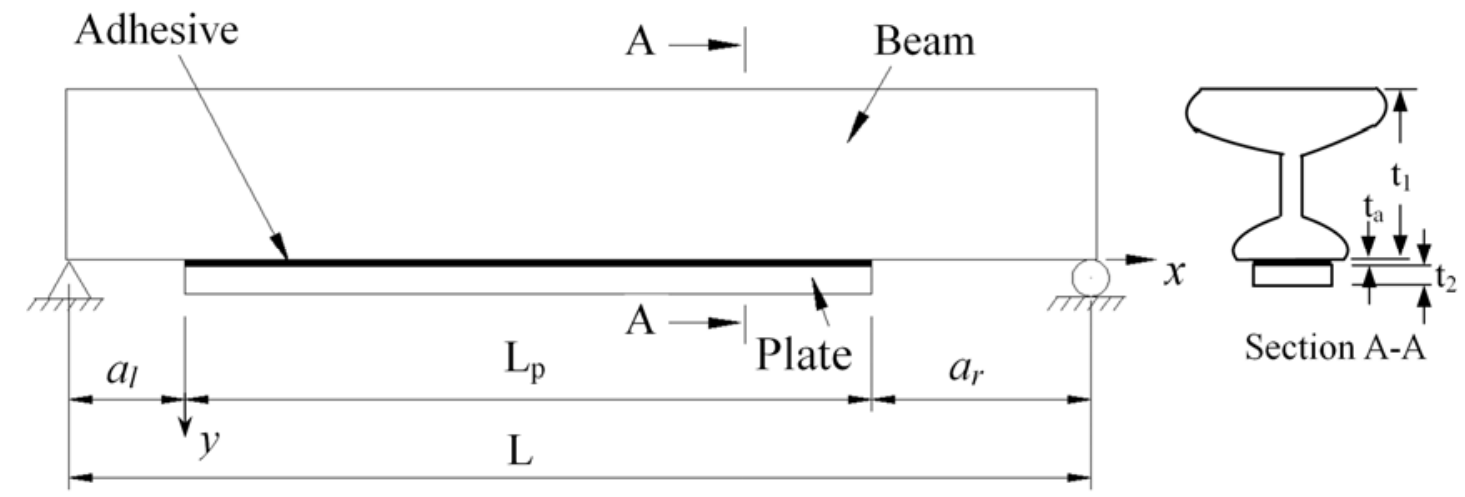

Fig. 1. Plated beam

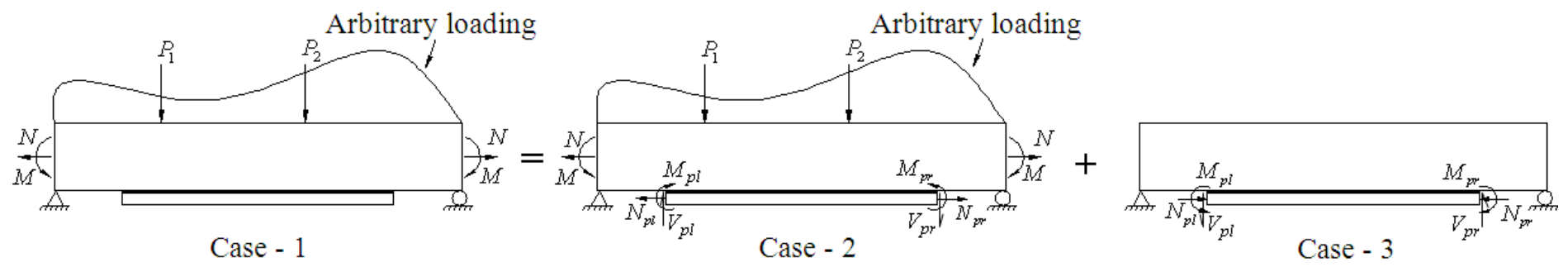

Solution for Case- 1 = Solution from $($ Case- $2+$ Case- 3$)$

Fig. 2. Principle of superposition in interfacial stress analysis of plated beam

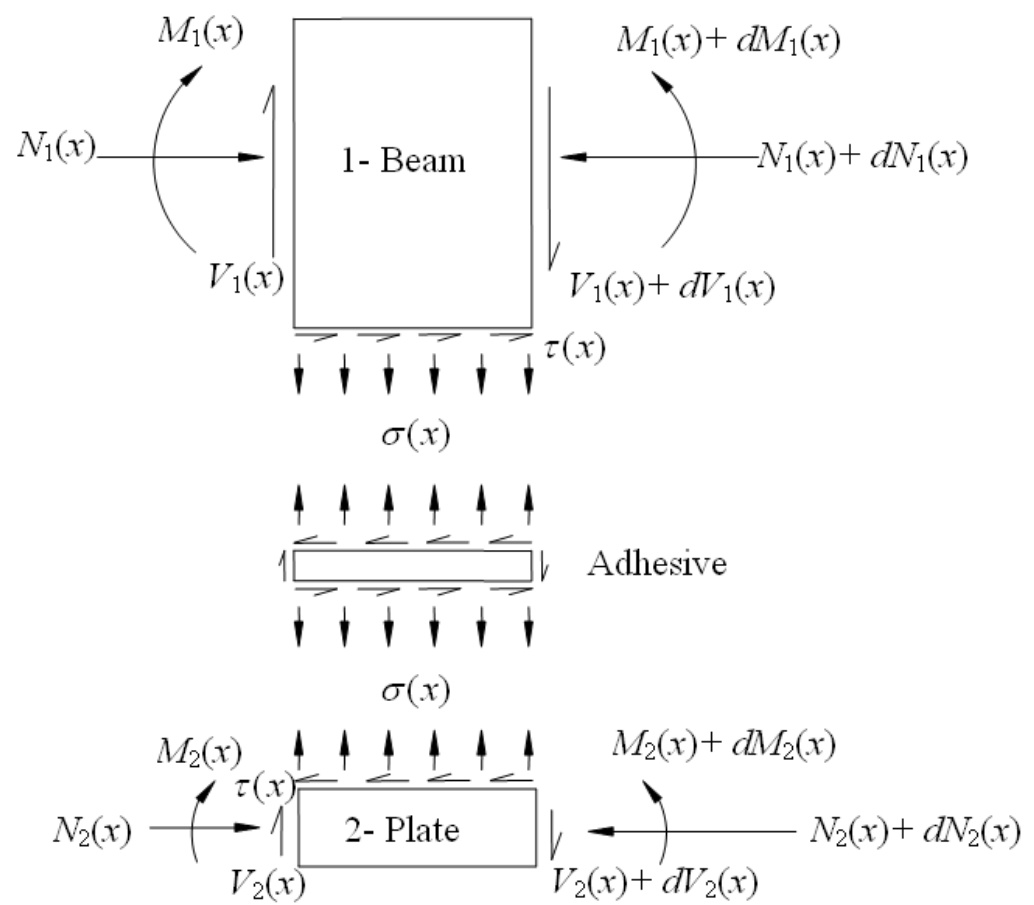

Fig. 3. Differential segment of a plated beam 


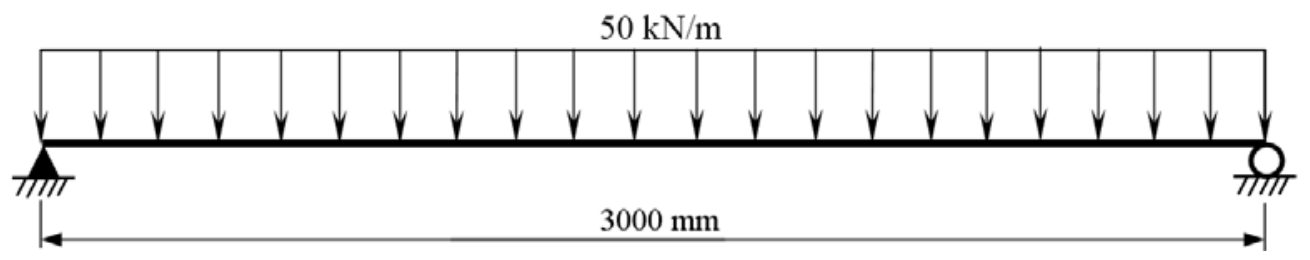

(a) Plated RC beam under UDL

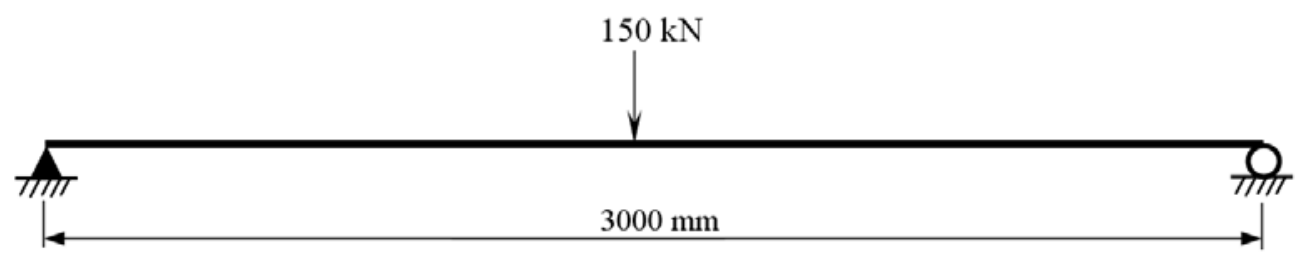

(b) Plated RC beam under mid-point load

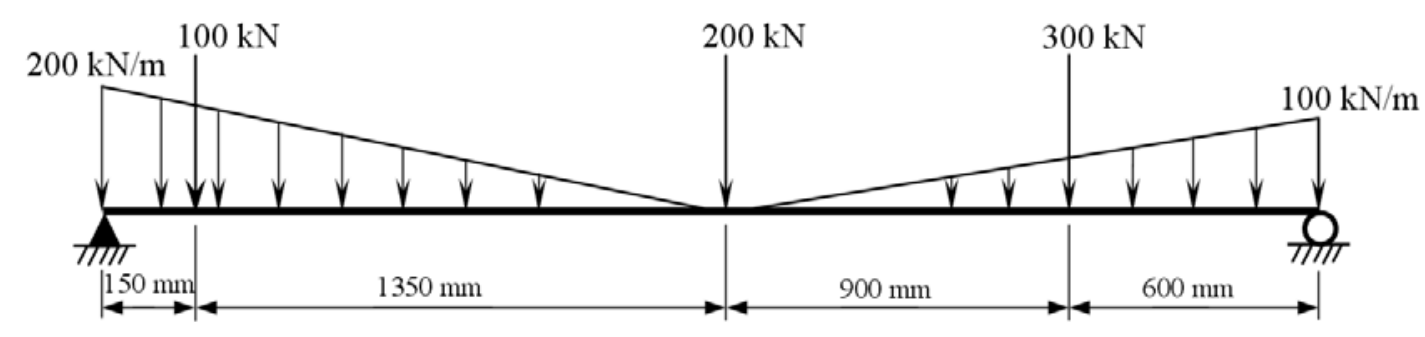

(c) Plated RC beam under complex load

Fig. 4 Loading examples on plated beams 


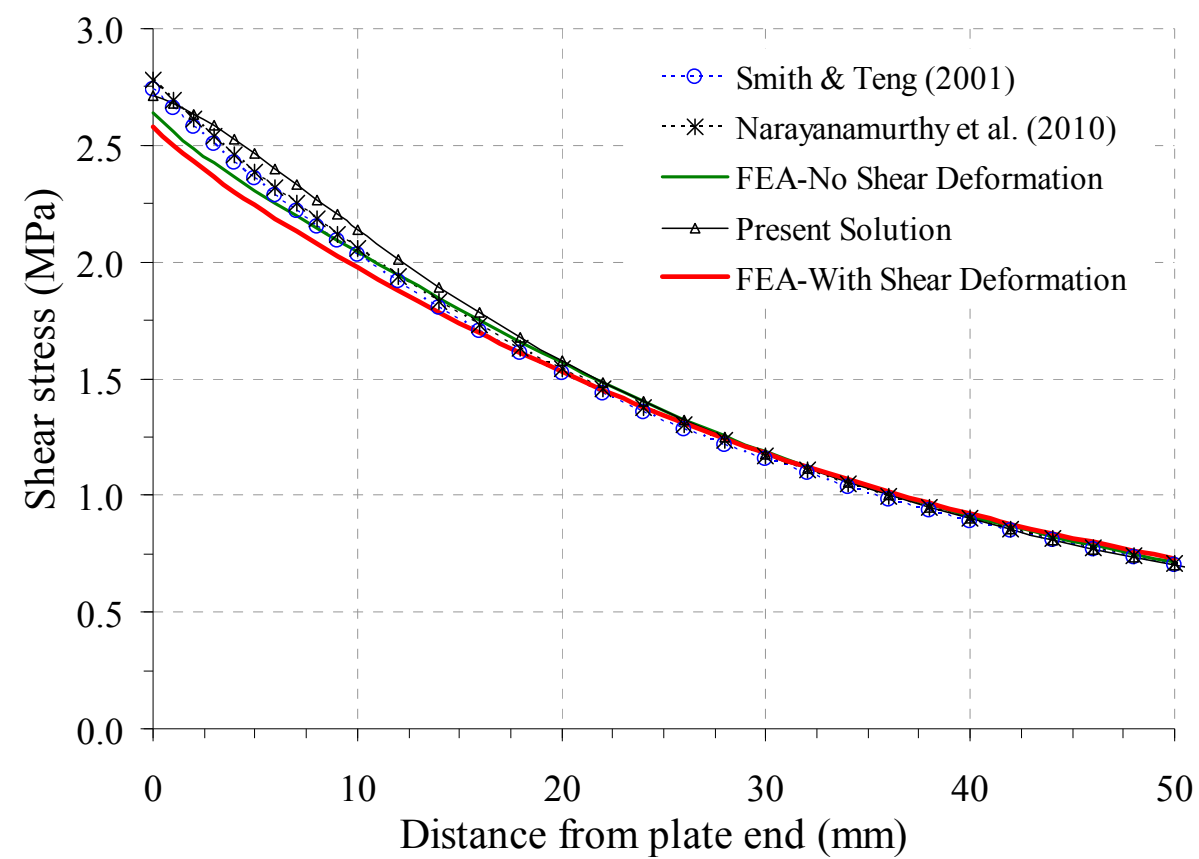

(a) Interfacial shear stress: present, FEA and reference solutions with no shear effect

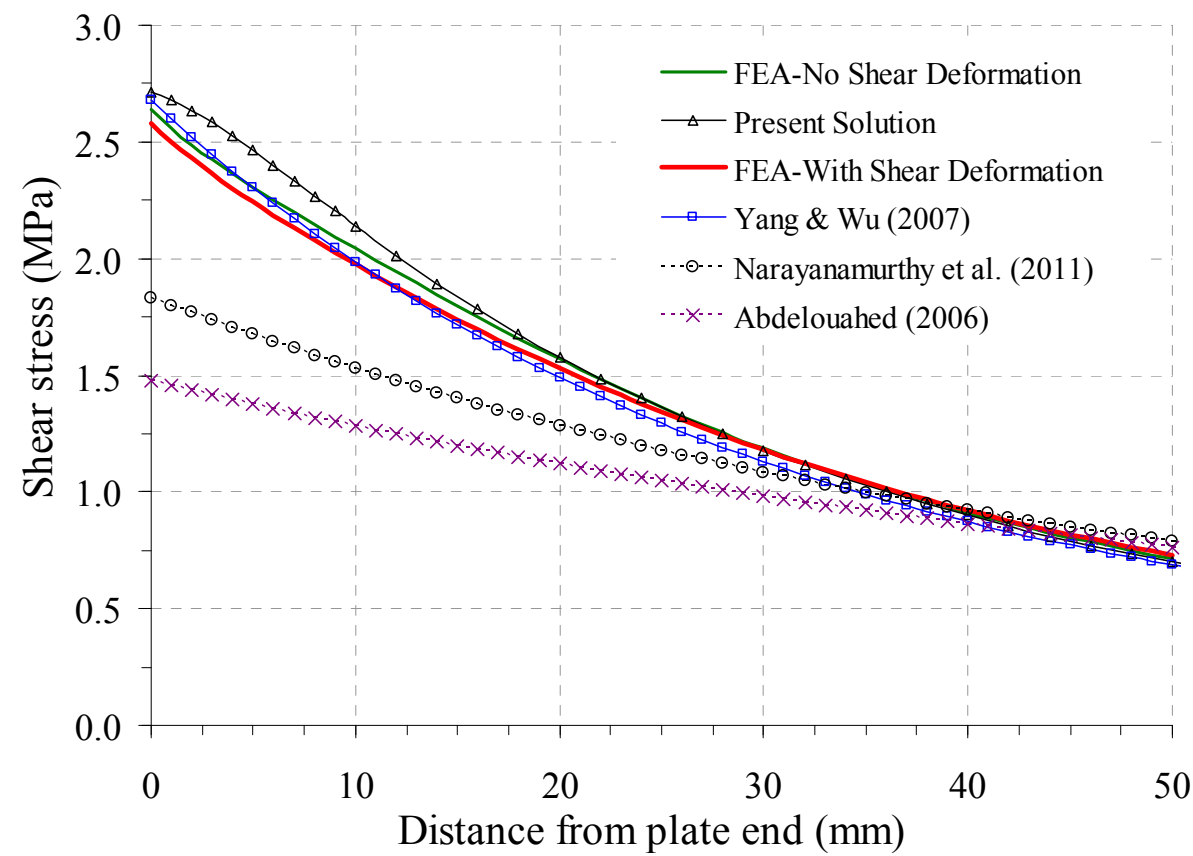

(b) Interfacial shear stress: present, FEA and previous solutions with shear effect 


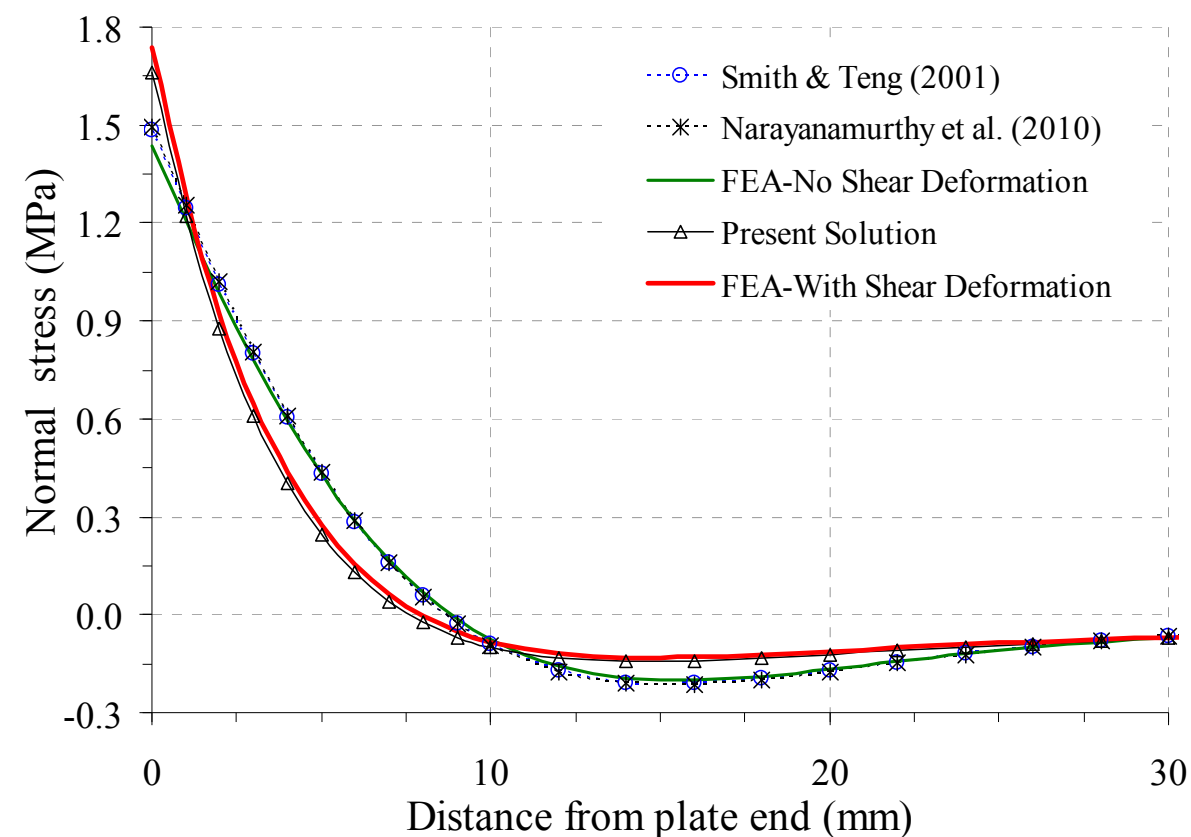

(c) Interfacial normal stress: present, FEA and reference solutions with no shear effect

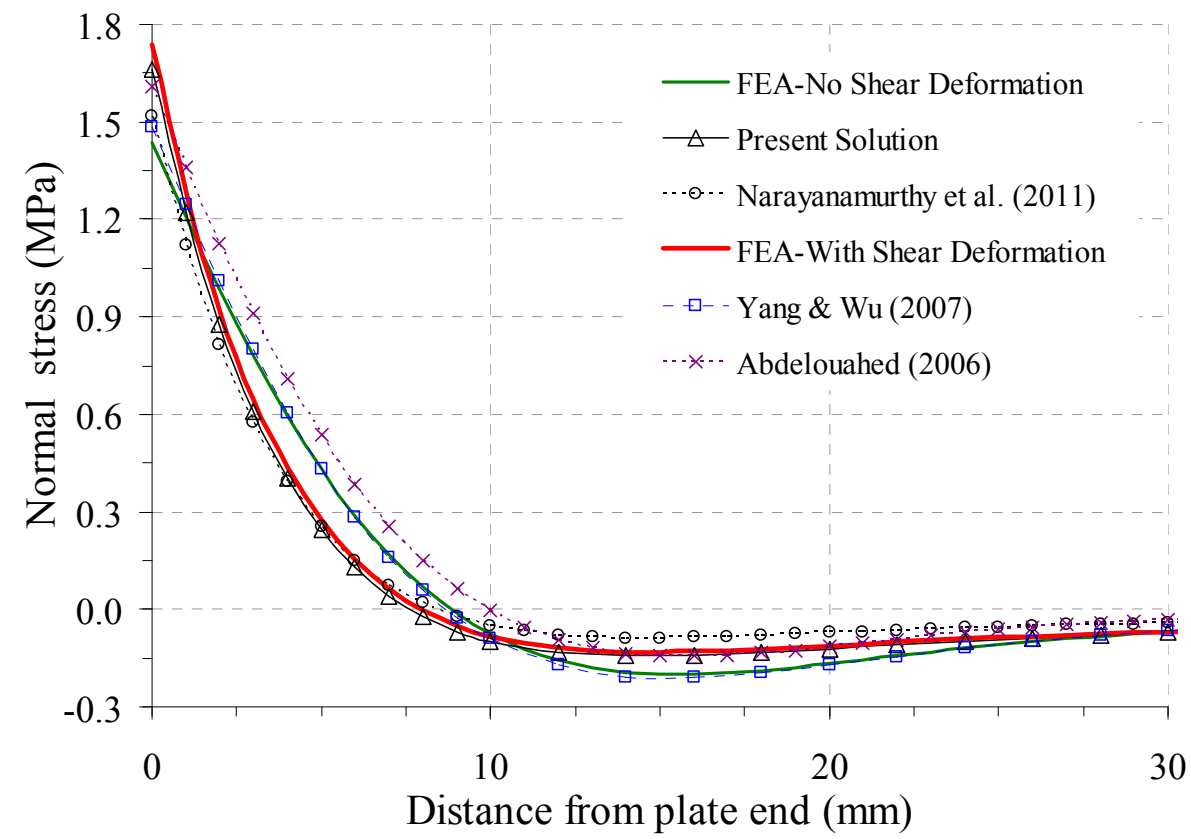

(d) Interfacial normal stress: present, FEA and previous solutions with shear effect

Fig. 5 Comparison of present, FEA and previous solutions for interfacial stresses in a CFRP plated RC beam subjected to an UDL 


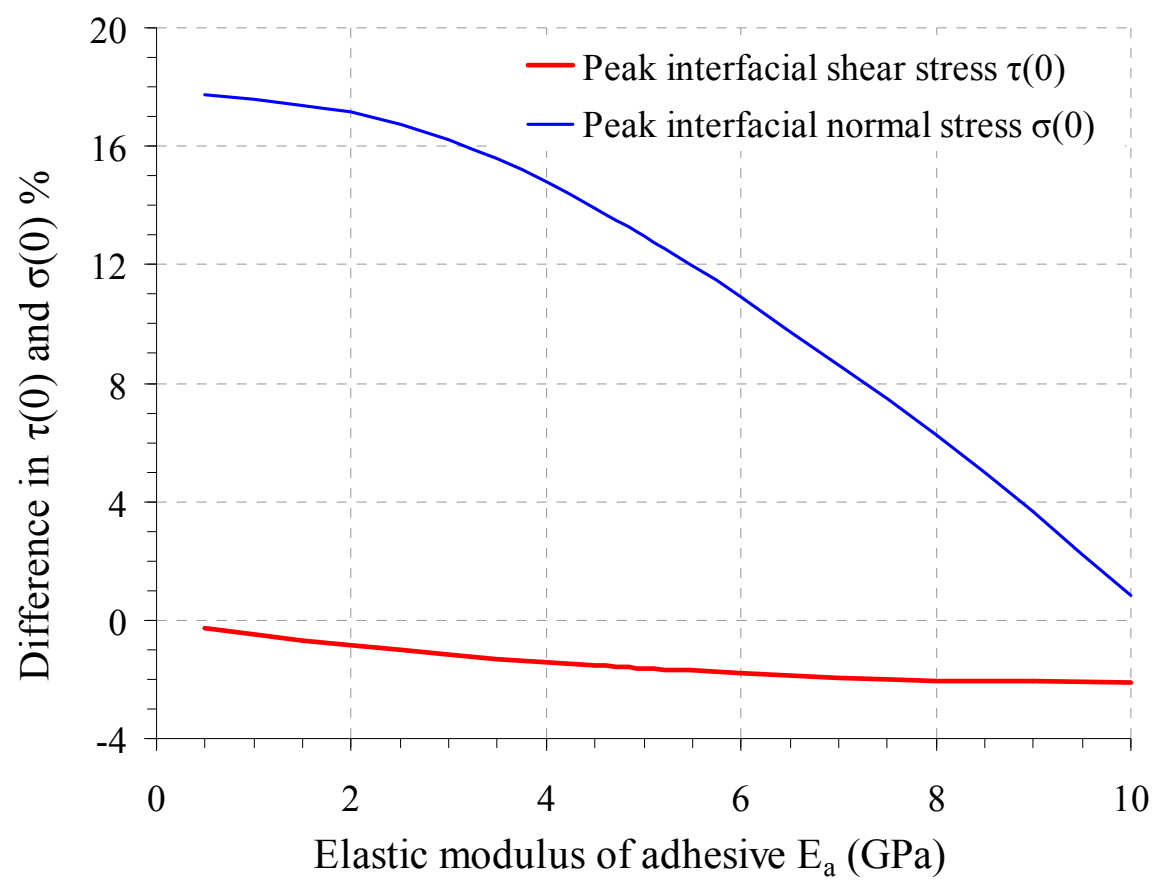

Fig. 6 Effect of adherends shear deformation on peak interfacial stresses for various elastic modulus of adhesive

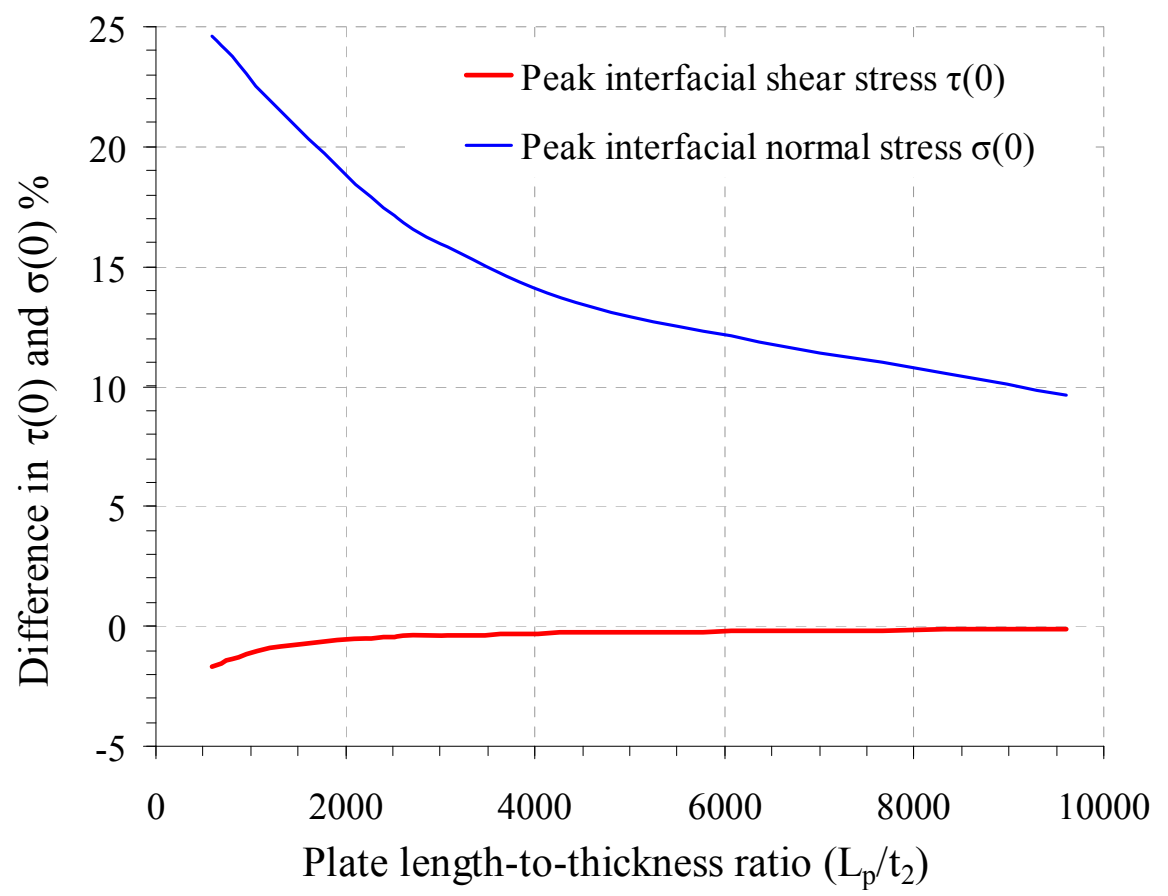

Fig. 7 Effect of adherends shear deformation on peak interfacial stresses for various plate thicknesses 
Table 1

Geometric and material properties of example plated beams

\begin{tabular}{llllll}
\hline \multicolumn{1}{c}{ Component } & $\begin{array}{c}\text { Width } \\
(\mathrm{mm})\end{array}$ & $\begin{array}{c}\text { Depth } \\
(\mathrm{mm})\end{array}$ & $\begin{array}{c}\text { Length } \\
(\mathrm{mm})\end{array}$ & $\begin{array}{c}\text { Elastic Modulus } \\
(\mathrm{GPa})\end{array}$ & $\begin{array}{c}\text { Shear Modulus } \\
(\mathrm{GPa})\end{array}$ \\
\hline RC beam & $b_{1}=200$ & $t_{1}=300$ & $L_{1}=3000$ & $E_{1}=30$ & $G_{1}=12.82$ \\
Adhesive layer & $b_{\mathrm{a}}=200$ & $t_{\mathrm{a}}=2$ & $L_{\mathrm{a}}=2400$ & $E_{\mathrm{a}}=2$ & $G_{\mathrm{a}}=0.74$ \\
GFRP plate & $b_{2}=200$ & $t_{2}=4$ & $L_{2}=2400$ & $E_{2}=50$ & $G_{2}=3.50$ \\
CFRP plate & $b_{2}=200$ & $t_{2}=4$ & $L_{2}=2400$ & $E_{2}=100$ & $G_{2}=4.24$ \\
\hline
\end{tabular}

Table 2

Peak interfacial stresses in plated RC beams under UDL (Fig. 4a), MPa

\begin{tabular}{|l|c|c|c|c|}
\hline Theory & \multicolumn{2}{|c|}{ GFRP plated } & \multicolumn{2}{c|}{ CFRP plated } \\
\hline & $\tau(x)$ & $\sigma(x)$ & $\tau(x)$ & $\sigma(x)$ \\
\hline $\begin{array}{l}\text { Roberts \& Haji-Kazemi (Solution-1) } \\
(1989)\end{array}$ & 2.001 & 1.425 & 2.776 & 1.668 \\
\hline $\begin{array}{l}\text { Roberts \& Haji-Kazemi (Solution-2) } \\
(1989)\end{array}$ & 1.813 & 1.256 & 2.591 & 1.500 \\
\hline Roberts (1989) & 1.945 & 1.386 & 2.604 & 1.567 \\
\hline Malek et al. (1998) & 1.943 & 1.384 & 2.597 & 1.563 \\
\hline Smith \& Teng (2001) & 1.975 & 1.244 & 2.740 & 1.484 \\
\hline Narayanamurthy et al. (2010) & 2.002 & 1.249 & 2.778 & 1.495 \\
\hline FEA- no shear deformation & 1.867 & 1.185 & 2.638 & 1.437 \\
\hline Yang \& Wu (2007) & 1.955 & 1.227 & 2.684 & 1.472 \\
\hline Abdelouahed (2006) & 1.042 & 1.366 & 1.475 & 1.606 \\
\hline Narayanamurthy et al. (2011) & 1.298 & 1.184 & 1.834 & 1.518 \\
\hline Present & 1.955 & 1.299 & 2.712 & 1.660 \\
\hline FEA- with shear deformation & 1.818 & 1.347 & 2.580 & 1.738 \\
\hline
\end{tabular}

Table 3

Peak interfacial stresses in plated RC beams under mid-point load (Fig. 4b), MPa

\begin{tabular}{|l|c|c|c|c|}
\hline Theory & \multicolumn{2}{|c|}{ GFRP plated } & \multicolumn{2}{c|}{ CFRP plated } \\
\hline & $\tau(x)$ & $\sigma(x)$ & $\tau(x)$ & $\sigma(x)$ \\
\hline Vilnay (1988) & 2.240 & 1.381 & 3.152 & 1.669 \\
\hline Roberts (1989) & 2.179 & 1.553 & 2.925 & 1.761 \\
\hline Taljsten (1997) & 2.215 & 1.397 & 3.087 & 1.674 \\
\hline Malek et al. (1998) & 2.179 & 1.553 & 2.925 & 1.761 \\
\hline Smith \& Teng (2001) & 2.214 & 1.396 & 3.083 & 1.671 \\
\hline Narayanamurthy et al. (2010) & 2.242 & 1.400 & 3.119 & 1.679 \\
\hline Present & 2.182 & 1.465 & 3.041 & 1.885 \\
\hline
\end{tabular}

Table 4

Peak interfacial stresses in plated RC beams under complex loading (Fig. 4c), MPa

\begin{tabular}{|l|c|c|c|c|}
\hline Theory & \multicolumn{2}{|c|}{ GFRP plated } & \multicolumn{2}{c|}{ CFRP plated } \\
\hline & $\tau(x)$ & $\sigma(x)$ & $\tau(x)$ & $\sigma(x)$ \\
\hline Narayanamurthy et al. (2010) & 8.977 & 5.599 & 12.070 & 6.493 \\
\hline Present & 8.748 & 5.758 & 11.770 & 7.140 \\
\hline
\end{tabular}

